\title{
The Environmental Effects of Cryptocurrencies
}

\author{
Shaen Corbet $^{a, b *}$, Larisa Yarovaya ${ }^{c}$ \\ ${ }^{a}$ DCU Business School, Dublin City University, Dublin 9, Ireland \\ ${ }^{b}$ School of Accounting, Finance and Economics, University of Waikato, New Zealand \\ ${ }^{c}$ Southampton Business School, University of Southampton, Southampton, SO17 1BJ, UK \\ *Corresponding Author: shaen.corbet@dcu.ie
}

\begin{abstract}
This chapter discusses the environmental aspects of cryptocurrency markets and as to how their rapid growth can influence the environment and through which channels this process manifests. While it is not popular discussion among investors, we find that environmental issues can be of interest by wider society, students, policy makers and stakeholders of FinTech companies. Environmentalism has a long history, and controversy around this subject is remains quite substantial, thus to not make our discussion over-complicated, in this chapter we will focus on the area where to date, we possess the most thorough data and evidence through which we can build the case, namely electricity consumption associated with the mining of cryptocurrencies. The total carbon footprint of the industry is now estimated to have surpassed that of many large industrial nations. This chapter investigates the multiple knock-on effects and consequential behaviour of this rapid growth in energy usage, such as an increase in global temperature, the growth of mining companies who have targeted third world infrastructures, and the complete shutdown of the internet as we know it. Saying that, we encourage investors not to ignore these environmentalism matters, since we also show that electricity consumption is proven to be one of the commonly used variable in valuation of mineable cryptocurrencies and identification of their fair value, which affect investments returns and should be considered in their trading strategies.
\end{abstract}

Keywords: Bitcoin; Cryptocurrencies; Volatility; Speculative Assets; Currencies; Energy Usage.

\section{Introduction}

As cryptocurrencies as a financial market product continue to evolve, it is becoming more certain that innovative solutions are going to be needed to solve some substantial forthcoming issues with regards to energy usage and technological capacity. The energy usage of Bitcoin mining has increased from 4.8Twh to 73.12Twh over the last two years, and the whole network now consumes 
more energy than Austria ${ }^{1}$. The estimated energy footprint per Bitcoin transaction is over $600 \mathrm{Kwt}$, which is estimated to be equivalent to over 300,000 contactless payment transactions, or to the power consumption of an average household for over 22 days. Bitcoin in its current form is a very expensive transmission mechanism. The major fuel used by these networks, due to its relatively majority-based Chinese point of origin, is coal-fired power plants, which has resulted in an extensive carbon footprint for each transaction. This raises questions about the environmental sustainability of cryptocurrencies. The participation in the validation and mining process of Bitcoin requires both special hardware and a substantial amount of energy, therefore, there is on-going carbon production. The computing power required to solve one Bitcoin has quadrupled throughout 2019, compared to the same period twelve months previous. This has led to some concern within the sector of the imminent need for broad international regulation in a bid to stall such exponential growth in energy usage. However, there are difficulties in providing definitive estimates. Further, the argument has been even more substantially muddied, as cryptocurrency proponents have stated that the usage of renewable energy has not been appropriately accounted for.

Research by Li et al. [2019] presented evidence through data analysis and experiments, that the estimated electricity for Monero, could consume 645.62GWh of electricity in the world in a single year after the hard fork. If there is $4.7 \%$ mining activity happening in China, the consumption is at least 30.34GWh, contributing a carbon emission of between 19.12 and 19.42 thousand tons in a single year. Stoll et al. [2019] utilised a methodology for estimating the power consumption associated with Bitcoin mining based on IPO filings of major hardware manufacturers. The authors then translate the power consumption estimates into carbon emissions, using the localisation of IP-addresses. As of late 2018, the authors estimate the electricity consumption of Bitcoin to be 48.2TWh, and estimate that annual carbon emissions range from 23.6 to $28.8 \mathrm{MtCO}_{2}$, similar to that produced by the nations of Jordan and Mongolia, a result that the authors consider to be conservative. Should other cryptocurrency markets such as Ethereum, Monero and zCash among others be considered, this figure could well double, a sum equivalent to that of Portugal. Further, Krause and Tolaymat [2018] had previously identified that that mining Bitcoin, Ethereum, Litecoin and Monero consumed an average of 17, 7, 7 and 14MJ of energy to generate one US\$, respectively. While presenting results largely in line with Stoll et al. [2019], it was also estimated that it took four times more energy for mining 1 US $\$$ of Bitcoin than it did to mine one US\$ of copper and double that of either platinum or gold. Mora et al. [2018] showed that when basing their calculations on projected Bitcoin usage, under the assumption that it follows the rate of adoption of other broadly adopted technologies, this new cryptocurrency had the potential to create enough $\mathrm{CO}_{2}$ emissions to push warming above 2 degrees Celsius within less than three decades.

While opponents of such estimates largely point towards the omission in such research of re-

\footnotetext{
${ }^{1}$ BitcoinEnergyConsumption.com, October 2019
} 
newable energy usage, it is highly probable given the relatively small share of renewable in most countries with large mining pools that the net effects of the growth of cryptocurrency is carbon positive and detrimental to our environment at its current rate of growth. Recent research has focused on issues such as the sharp growth in cybercriminality (Corbet et al. [2019]), and the use of cryptocurrency for illicit purposes (Foley et al. [2019]), but little research to date has been done on the environmental impacts of cryptocurrencies (Truby [2018]; Easley et al. [2019]; Greenberg and Bugden [2019]; Li et al. [2019]).

\subsection{Why should we care about the environmental effects of cryptocurrencies?}

It is not surprising that environmental aspects are often put aside in finance academic literature and financial industries. While there are many goals that enterprise may have, firms in the financial sector are less likely to directly aim at environmental actions without incentivisation, such as improving air and water quality, wildlife and habitats protection. Investment companies and funds are interested in maximising financial returns and decreasing the risks of investments, while incorporation of environmental goals and values into their strategy in majority of cases seems unnecessary, excessive, and most importantly, too expensive. This is also reflected in the finance research and papers published in reputable finance journals, where the majority of those analysing the risk-return characteristics of financial assets rather than the environmental implications of their growth. However, the situation is ever evolving. With elevated attention to the importance of the environment among society, and acknowledgement of the climate change issues facing society by the majority of governments and institutions worldwide, we observed emergence of environmental and climate finance field, as well as expansion of the research addressing urgent multidisciplinary research questions in finance and environmental science simultaneously. Corporate social responsibility matters shaped not only business and accounting processes, but further encouraged emergence of various ethically-cleansed financial assets and instruments, that are available for investors, which cause the changes in their investment objectives. The investors more often follow the ethical values and beliefs in making investment decisions, and environmental factors could be a strong influence.

As to whether cryptocurrency investors care about the carbon footprint of this industry and its environmental impacts is a significant question. We can only guess, but the easiest assumption to make here is that they do not care about it. If they do care about the increased mining difficulty and electricity consumption, then only in the context of the increased cost of mining and its impact on the prices and consequentially investment returns, while wider environmental impacts might be not considered. The majority of mining pools are situated in China and around $80 \%$ of Bitcoins minded there, followed by $10 \%$ in Czech Republic, and Iceland, Japan, Georgia and Russia account approximately $2 \%$ of network hashrate each. The location of mining pools matters due to the energy sources, environmental standards, and clean energy alternatives available in the countries. 
Not only the power consumption itself is important, but also energy sources which determine the carbon footprint of this industry.

According to Mora et al. [2018] cumulative Bitcoin mining emissions likely to warm the planet by 2 degrees Celsius within 22 years if the current rate is similar to some of the slowest broadly adopted technologies, or within 11 years if adopted at the fastest rate at which other technologies have been incorporated. However, this estimates are based on assumption that the sources of fuel will be fixed and remained unchanged over the target period of time.Thus, it is still possible to decrease the environmental impacts of Bitcoin mining and it is critical to explore the ways to decrease the carbon footprint of cryptocurrencies.

\subsection{Technological vs Ecological Environmentalism}

The nature of debates around any new technological development can be better understood if by referring to an early study by O'Riordan [1985] who discussed the differences between technological and ecological environmentalism, comparing technocentrists and ecocentrists viewpoints and beliefs. Technocentrism denotes that humans and technologies can impact environment, and by using adequate management we can minimise the negative impacts of economic growth on nature. This assumes that humans relationships with environment related to utility and usefulness of resources that are provided by nature. Thus, as individuals and as society we would care about negative impacts on environment only if we are directly benefiting from it and our negative impacts are subsequently reducing those benefits. In contrast, ecocentrism provides more romanticised interpretation of environmental protection suggesting that it's moral obligation of all human kinds to respect and protect the nature regardless of its use and its value referring to wild nature as to integral companion of man. Thus, people should try to avoid causing any harm to nature and environments since they are directly harming their own natural habitat.

\subsection{Are all cryptocurrencies equally bad for the environment?}

There are various digital currencies available and some of those are less energy consuming than others. A useful classification of the digital assets provided by Corbet et al. [2020a] who explained that financial cryptocurrencies that are intended solely for the transfer of wealth and to be used

as payments systems, are just one of the possible applications on the top layer of the blockchain stack. Authors classify each digital asset in one of three categories:

1. Currencies: Digital assets whose primary (and in most cases, only) use is that of financial payment or monetary transfer.

2. Blockchains/Protocols: Digital assets whose primary usage is that of a blockchain platform, or protocol, on which other applications can be built.

3. Decentralised Applications (dApps): Applications combining a user interface, and a decentralised back-end, built upon an already existing blockchain. 
For the first category, digital currencies, to possess value, they must be scare, a shortcoming of all previous attempts at creating digital currencies. The mining process creates, and ensures scarcity. Miners allocate resources, in the form of computing power, to this pursuit, in the hope of receiving a block reward (a payment of Bitcoin to the first node to arrive at the correct solution to the mathematical problem). Digital assets derive their value, and the scarcity necessary for value, from this mining process. Digital assets can be stored using a variety of methods: online wallets, online exchanges, hardware wallets and paper wallets (cold storage) being just a selection of the possible storage methods.

Thus mining process is what mainly cause the environmental unsustainability of the digital currencies. Bitcoin is the most well-known, but not the only mineable cryptocurrency that is currently traded. Another popular mineable cryptocurrency is Ether which is built on Ethereum protocol. Ethereum use the same proof-of-work algorithm as Bitcoin, and even though the carbon footprint per transaction is lower, the entire Ethereum network also consumes the amount of electricity comparable with whole countries. Overall, all cryptocurrencies can be divided by mineable and non-mineable currencies.

\section{Proof-of-work algorithm}

\subsection{Bitcoin mining}

Bitcoin's trust-minimising consensus has been enabled by its proof-of-work algorithm. The machines completing the algorithms consume substantial amounts of energy while completing their tasks. New sets of blocks are added to Bitcoin's blockchain approximately every 10 minutes by miners. The code that supports Bitcoin includes several rules to validate new transactions. Every miner individually confirms whether transactions adhere to these rules, eliminating the need to trust other miners, instead trusting the process. Every miner in the network is constantly tasked with preparing the next batch of transactions for the blockchain. Only one of these blocks will be randomly selected to become the latest block on the chain.

In proof-of-work, the next block comes from the first miner that produces a valid one. The difficulty is regularly adjusted by the protocol to ensure that all miners in the network will only produce one valid block every 10 minutes on average. Once one of the miners finally manages to produce a valid block, it will inform the rest of the network and other miners will accept this block once they confirm it adheres to all rules, and then discard whatever block they had been working on themselves. The lucky miner gets rewarded with a fixed amount of coins, along with the transaction fees belonging to the processed transactions in the new block. Then the cycle begins once again.

The continuous block mining cycle incentivises miners to mine Bitcoin. As mining can provide a solid stream of revenue, these miners are very willing to run machines that consume substantial amounts of energy in an attempt to generate reward. Over the years this has caused the total 
energy consumption of the Bitcoin network to grow to unsustainable levels, as the price of the currency reached new highs. It is widely considered that Bitcoin alone uses more power when mining than that of countries such as the Philippines, Chile, Venezuela, the Czech Republic and Austria. Bitcoin's biggest problem is perhaps not even its massive energy consumption, but the fact most mining facilities in Bitcoin's network are located in regions that rely heavily on coal-based power. A Bitcoin ASIC miner will, once turned on, not be switched off until it either breaks down or becomes unable to mine Bitcoin at a profit. Because of this, Bitcoin miners increase both the baseload demand on a grid, as well as the need for alternative (fossil-fuel based) energy sources to meet this demand when renewable energy production is low. In the worst case scenario, the presence of Bitcoin miners may thus provide an incentive for the construction of new coal-based power plants, or reopening existing ones. This impact would be even harder to quantify.

In late 2017, Credit Suisse estimate that a bitcoin price of $\$ 50,000$ would increase the electricity consumption tenfold. And at a bitcoin price of $\$ 1.1 \mathrm{~m}$, it would be profitable to use almost all the electricity currently generated in the world for mining. The bank views the latter prospect as not worth worrying about, for two reasons: it doesn't think bitcoin will ever reach that value, since the competition from other cryptocurrencies is too strong; and it thinks that power consumption of mining will fall over time as better technologies are used for miners. Credit Suisse explicitly compares bitcoin to marijuana cultivation and data centres, two other industries that once sparked fears they would have huge power draws.

\subsection{Ethereum}

The power usage of Bitcoin is somewhat in contrast to that of other large cryptocurrencies such as Ethereum. Ethereum has plans to change its proof-of-work algorithm to an energy efficient proof-of-stake algorithm called Casper. This change would minimise energy consumption and will be implemented gradually. For now, Ethereum is still running on proof-of-work completely. In its current state the entire Ethereum network consumes more electricity than a number of countries, based on a report published by the International Energy Agency while Bitcoin had been estimated to use 73TWh per year, Ethereum's power usage was substantially lower at $7.65 \mathrm{TWh}$ per year. Proof-of-work was the first consensus algorithm that managed to prove itself, but it is not the only consensus algorithm. More energy efficient algorithms, like proof-of-stake, have been in development over recent years. In proof-of-stake coin owners create blocks rather than miners, thus not requiring power hungry machines that produce as many hashes per second as possible. Because of this, the energy consumption of proof-of-stake is negligible compared to proof-of-work. Bitcoin could potentially switch to such an consensus algorithm, which would significantly improve sustainability. The only downside is that there are many different versions of proof-of-stake, and none of these have fully proven themselves yet. Nevertheless the work on these algorithms offers good hope for the future. 
As cryptocurrency markets continue to develop, it is to be expected that solutions are imminently necessary to solve some substantial forthcoming issues. The energy use of Bitcoin mining has increased from 4.8 Twh to 68.9 Twh over the last two years and the whole network now consumes more energy than Czech Republic. The energy footprint per Bitcoin transaction is now in excess of $500 \mathrm{Kwt}$, which is equivalent to 350,000 visa transactions. Energy wise, Bitcoin in an expensive transmission mechanism. Nowadays, most mining pools, i.e. groups of miners working in specialised warehouses with extensive amounts of mining hardware, are situated in China. The major fuel used by these networks is thus from coal-fired power plants, which results in an extensive carbon footprint for each transaction. Some estimates say more than 60 percent of the processing power used to mine bitcoin is in China, where it relies heavily on the burning of coal. An estimated $85 \%$ of cryptocurrency mining occurs in China, where electricity is cheap and largely sourced from environmentally unsustainable sources like coal-powered plants. As the cryptocurrency industry grows, and the adoption of blockchain technology increases, it is increasingly important for cryptocurrencies' blockchain technology to be more environmentally conscious. By prioritising efficiency, these new cryptocurrencies also reduce their environmental impact. In doing so, the industry neatly exemplifies how improving the environmental output of an industry can be linked to enhanced productivity and effectiveness. Coal and other fossil fuels are also the largest generator of electricity for the rest of the world, and coal is a significant contributor to man-made climate change. Burning it produces carbon dioxide, a gas that is a primary contributor to global warming. This reliance on fossil fuels has given rise to speculation that bitcoin's energy consumption will continue to rise as it grows in popularity. This raises questions about the environmental sustainability of cryptocurrencies.

Participation in the validation and mining process of Bitcoin requires both special hardware and a substantial amount of energy. Thus there is embedded carbon and ongoing carbon production. The computing power required to solve one Bitcoin as of 2019 has quadrupled compared to twelve months previous. Evidence of this substantial growth in difficulty is presented in Figure 1. This has led to some concern within the sector of the imminent need for broad international regulation in a bid to stall such exponential growth in energy usage. However, there are difficulties in providing definitive estimates and the argument has been even further muddied as cryptocurrency proponents have stated that the usage of renewable energy has not been appropriately accounted for.

\section{Insert Figure 1 about here}

The rest of this chapter is as follows. Section 3 presents a thorough review of the literature relating to the growth of energy usage within the cryptocurrency sector along with the main identified issues that exist today. Section 4 presents an overview released data to date, with associated commentary as to what the trends have being presenting and as to whether multiple sources are generating the same conclusions. Section 5 outlines and explains the multiple issues that have been 
identified to date. Section 6 presents a concise overview of the proposed solutions to the analysed issues, while Section 7 concludes.

\section{Previous Literature}

Research by Stoll et al. [2019] utilised a methodology for estimating the power consumption associated with Bitcoin mining based on IPO filings of major hardware manufacturers, insights on mining operations, and mining pool compositions. The authors then translate the power consumption estimates into carbon emissions, using the localisation of IP-addresses. As of late 2018, the authors estimate the electricity consumption of Bitcoin to be $48.2 \mathrm{TWh}$, and estimate that annual carbon emissions range from 23.6 to $28.8 \mathrm{MtCO}_{2}$, similar to that produced by the nations of Jordan and Mongolia, a result that the authors consider to be conservative. Should other cryptocurrency markets such as Ethereum, Monero and zCash among others be considered, this figure could well double, a sum equivalent to that of Portugal. Krause and Tolaymat [2018] had previously identified that that mining Bitcoin, Ethereum, Litecoin and Monero consumed an average of 17, 7, 7 and $14 \mathrm{MJ}$ of energy to generate one US\$, respectively. While presenting results largely in line with Stoll et al. [2019], it was also estimated that it took four times more energy for mining 1 US\$ of Bitcoin than it did to mine one US\$ of copper and double that of either platinum or gold. Mora et al. [2018] showed that when basing their calculations on projected Bitcoin usage, under the assumption that it follows the rate of adoption of other broadly adopted technologies, this new cryptocurrency had the potential to create enough $\mathrm{CO}_{2}$ emissions to push warming above 2 degrees Celsius within less than three decades.

While opponents of such estimates largely point towards the omission in such research of renewable energy usage, it is highly probable given the relatively small share of renewable in most countries with large mining pools that the net effects of the growth of cryptocurrency is carbon positive and detrimental to our environment at its current rate of growth. This research sets out to specifically investigate as to whether the price volatility effects of such cryptocurrencies, proxied by Bitcoin, has generated dynamic correlations with electricity and utilities providers in countries that contain the largest international mining pools. Such increased demand through the cryptocurrency mining process should theoretically manifest in changing financial dynamics for these identified companies. We have also selected to investigate as to whether any dynamic relationship exists between Bitcoin and the markets for green energy ETFs and the market for ICE EUX Carbon

Credits, where one lot of 1,000 $\mathrm{CO}_{2}$ EU Allowances provides an entitlement to emit one tonne of carbon dioxide equivalent.

Recent research has focused on issues such as the sharp growth in cybercriminality (Corbet et al. [2019]), and the use of cryptocurrency for illicit purposes (Foley et al. [2019]), but little research to date has been done on the environmental impacts of cryptocurrencies (Truby [2018]; 
Easley et al. [2019]; Greenberg and Bugden [2019]; Li et al. [2019]). Further, there is much evidence to suggest that this new financial product has continued to progress with evidence provided of growing efficiency (Bariviera [2017]) and product and pricing enhancement through the use of related derivatives products (Corbet et al. [2018]; Akyildirim et al. [2019]). While the main stream of cryptocurrency research is currently focused on the dilemma as to whether this is a currency or speculative asset (Baur et al. [2018]); and conducting analysis of the multiple forms of pricing inefficiencies (Urquhart [2017]; Sensoy [2019]; Mensi et al. [2019]; Katsiampa et al. [2019]), Corbet et al. [2019] have provided a concise systematic review of the literature associated with cryptocurrency markets at large, and note that more research is needed to assess environmental and energy use issues. As this new financial product continues to develop through improved market efficiency (Ekinci et al. [2019]; Corbet et al. [2020b]) and portfolio design (Akhtaruzzaman et al. [2019]; Corbet et al. [2018]), it is imperative that we continue to understand the true risks associated. While considering the broad improvement in pricing efficiency and market efficiency, indicative of a rapidly developing financial market product, our paper assesses the financial long terms impacts of Bitcoin energy usage.

In Figure 1, we present the 1) mining difficulty; 2) hashrate; 3) the number of daily transactions; 4) the number of unique Bitcoin mining addresses and 5) block size of Bitcoin. Through each particular variable, we observe the growing maturity of this new financial product over time. Mining difficulty reflects how difficult it is to find a new block compared to the easiest that it could be, recalculated every 2016 blocks to a value such that the previous 2016 blocks would have been generated in exactly two weeks had everyone been mining at the same difficulty. As more miners join, the rate of block creation will increase, which causes the difficulty to increase in compensation to push the rate of block creation back down. A hash is the output of a hash function, and the hashrate is the speed at which a compute is completing an operation in the Bitcoin code. A higher hashrate when mining increases your opportunity of finding the next block and receiving the reward. The increased difficulty in mining has led to a need for more powerful technology and increased energy usage to mine cryptocurrency. Of course, the source of this additional required energy is central to the issues that Bitcoin, among other cryptocurrencies, faces.

Due to the growing number of mining pools across the world, we focus specifically on the six largest. China accounts for $81 \%$ of mining pool concentration, the Czech Republic 10\%, while Iceland, Japan, Georgia and Russia account for $2 \%$ respectively. After a thorough analysis, only China, Japan and Russia possess publicly traded electricity companies or core utility companies that trade primarily in energy. Further, there have been issues identified with the very nature of such concentration. Stoll et al. [2019] found that the four largest Chinese pools now provide almost $50 \%$ of the total hashrate, with Bitcoin operating three of such pools. 


\section{What does the data tell us?}

As of December 2019, it has been estimated that annualised global revenue available through the mining of Bitcoin alone was estimated to be $\$ 5.4$ billion. The global estimated cost to generate this revenue is approximately $\$ 3.9$ billion. Consider this, with one cryptocurrency, the potential rewards for mining is a spoil of a pool of $\$ 1.5$ billion. Considering the incredibly rapid growth in the number of cryptocurrencies that exist today, it is easy to comprehend as to how large this market, and the profits that exist for the most efficient miners in the market. It is this market efficiency that has come into sharp focus with costs accounting for approximately $70 \%$ of revenues. Much of the cost surrounds the technological challenges that miners face. In terms of mining cryptocurrency, substantial energy is allocated towards heat reduction. Countries with warmer climates have been broadly linked with substantial technological issues and machine malfunctions. While considering that a basic miner can use approximately 1,500 watts per hour, much of this energy is converted directly to heat output, which can be in excess of 5,000BTU per hour. When considering the fact that some mines possess up to 5,000 of these miners in close proximity, it is very easy to quickly identify the scale of the temperature issues that are faced. The task is not aimed at cooling the air, but rather to evacuate it from the areas surrounding the miners using industrial fans. Evaporative coolers are then used to cool the physical infrastructure surrounding the miners, controlling for moisture and evaporation from the heat exchange which can create disastrous consequences for the electrical infrastructure. If for example, a mine consumes 40MW of electricity per hour, and given an energy consumption of about 1,500 watts per hour per Bitcoin mining machine, these miners can consume over $75 \%$ of the electricity consumption with regards to the cryptocurrency mining process. Therefore, the cooling process of the miners can account for up to $25 \%$ of the total energy usage costs of a mine. We must further consider as to how hard these miners are working. In some cases, to reduce machine wear-and-tear, some miners are set to run below their maximum operating capacity. This would cause such cooling estimates to vary quite considerably. For example, some mining machines have controllers that gauges the ambient temperature and sets the fan speed and the voltage and clock speed of the machine accordingly. During periods of warm weather, this process will result in mining machines running at slower speeds (as measured in terahashes per second) to keep the chips cooler and reduce the risk of significant damage.

Stoll et al. [2019] found directly estimated the significant carbon footprint. The authors demonstrated a methodology for estimating the power consumption associated with Bitcoin's blockchain based on IPO filings of major hardware manufacturers, insights on mining facility operations, and mining pool compositions. We then translate our power consumption estimate into carbon emis-

sions, using the localisation of IP addresses. We determine the annual electricity consumption of Bitcoin, as of November 2018, to be $45.8 \mathrm{TWh}$ and estimate that annual carbon emissions range from 22.0 to $22.9 \mathrm{Mt} C O^{2}$. However, this validation process uses this 'vast amounts of electricity', to earn cryptocurrency without spending any money. To estimate the electricity consumption, the authors 
used IP addresses and hardware data from recent IPO filings. The authors wrote that their study points to potential drawbacks of blockchain technology that should be considered by policymakers. As of late 2019, the total network hashrate $(1,000,000 \mathrm{GH} / \mathrm{s})$ was estimated to be $121,669 \mathrm{PH} / \mathrm{s}$ with an estimated energy footprint per transaction of $640 \mathrm{KW} / \mathrm{h}$. This is found to represent almost 7.2 million households that could be powered by the equivalent energy that Bitcoin is accounting for, or otherwise 22 households could be powered for one day by the electricity consumed for a single transaction. This indicates that Bitcoin's electricity consumption ${ }^{2}$ as a percentage of the world's electricity consumption was estimated to be $0.35 \%$, with an annual carbon footprint $36,947 \mathrm{kt}$ of $\mathrm{CO}_{2}$, with a carbon footprint per transaction $303 \mathrm{~kg}$ of $\mathrm{CO}_{2}$.

\section{Insert Figures 2 through 5 about here}

To analyse the sectoral growth of Bitcoin since 2009, we present a number of characteristics surrounding this new product in Figures 2 through 5. As Bitcoin obtained more attention as a new financial product, its internal structure changed quite substantially. With this added attention developed a sharp increase in the number of transactions, trading volume and mining processes associated. In Figure 2 we identify the number of Bitcoins in circulation, with evidence of sharply elevated growth rates in the period between 2010 and 2013. However, in the period since 2017, this growth rate has somewhat plateaued. In Figure 3, we observe the USD $(\$)$ exchange traded value of Bitcoin. As expected, during the sharp price appreciation of late-2017, the value of the market grew from approximately $\$ 1$ billion to almost $\$ 5$ billion. In Figure 4 , we observe some of the key statistics with regards to blockchain size. As of late-2019, the blockchain size of Bitcoin grew above $250 \mathrm{~GB}$, while the average block size exceeded 1.20MB per transaction. In Figure 5, we observe the average number of transactions per block which has consistently exceeded 1,000 transactions since late 2015, and has been above 2,000 transactions since mid-2018. Throughout 2019, the median confirmation time has averaged approximately seven minutes, which was the consistently average range experienced between 2013 and late-2017. Miner's revenue has also be consistently above $\$ 5,000$ since Q2 2017, peaking during the period in which Bitcoin prices almost reached $\$ 20,000$.

\section{Insert Figures 6 through 8 about here}

In Figure 6, we observe the key statistics with regards to transaction fees in the market for Bitcoin. We observe that the total transaction fees grew quite substantially during periods of sharp price appreciation, reaching over $\$ 20$ million in late-2017. However, we also observe that cost as a

\footnotetext{
${ }^{2}$ Data obtained from https://digiconomist.net/bitcoin-energy-consumption
} 
proportion of the transaction volume has sharply declined over time while the cost per transaction has increased to a sustained high level since early-2017. In Figure 7, we can clearly identify the sharp growth in interest in the mining of Bitcoin as a product. There has been a consistent level of growth in the number of unique addresses mining the product, peaking during the largest price appreciations in Bitcoin. The has been echoed by the confirmed transactions per day in Bitcoin and the total number of transactions. In Figure 8, we see the behaviour of the number of unspent transaction output (UTXO) which is an abstraction of Electronic Money. Each UTXO represents a chain of ownership implemented as a chain of Digital Signatures where the owner signs a message (transaction) transferring ownership of their UTXO to the receiver's Public Key. The total UTXOs present in a blockchain represent a set, every transaction thus consumes elements from this set and creates new ones that are added to the set. The set thus represents all the coins in the system. In early-2018, while Bitcoin prices starts to decline from lifetime highs, the UTXO declined in a similar fashion, remaining elevated during some periods of short-term panic in mid-2019, but being quite low otherwise. Further, the mempool size, representing the aggregate size of transactions waiting to be confirmed has had a number of short-term spikes value over the past three years as measured in bytes per second. These large spikes can indicate that a number of miners have left the process. Further, the spike could also mean that the Bitcoin protocol is under threat, simply because transactions are not processing at their usual pace. It is also possible that the spike is because someone is spamming the network on purpose, to either raise fees or prevent certain transactions from processing.

\section{Insert Figures 9 through 11 about here}

We observe the number of unspent transaction outputs in Figure 9, which has been at a lifetime high of almost 70 million outputs in late-2019. Further, we observe the output value, which contains instructions for sending bitcoins. The value is the number of Satoshi $(1 \mathrm{BTC}=100,000,000$ Satoshi) that this output will be worth when claimed. ScriptPubKey is the second half of a script and there can be more than one output, and they share the combined value of the inputs. Because each output from one transaction can only ever be referenced once by an input of a subsequent transaction, the entire combined input value needs to be sent in an output if you don't want to lose it. There have been a number of distinct, sharp increases in this value, most notably in early-2016 and mid-2019. In Figure 10, we observe that the estimated transaction value has reduced consistently over time, however, as the price of Bitcoin increased, so did the estimated USD $(\$)$ transaction value. Finally, Figure 11 presents the user count of blockchain wallet users over time. We can clearly see a sharp growth of user numbers in the period since 2014, peaking in excess of 45 million in the period since early-2019. 
Insert Table 1 about here

In Table 1 we observe the international estimates of international electricity consumption (as of the most recent estimates in 2017). We observe that China is the largest consumer of electricity in the work, estimated to be in excess of 6.3 trillion $\mathrm{kW}$ hours per year. This is followed by the United States, then India, Russia and Japan. It is important to note that Japanese power consumption is almost twice that of the next group of countries that includes Germany, Canada, Brazil and South Korea. When considering the average electrical energy usage per capital, we observe a considerable change in the above rankings. Norway is the most significant user as measured per person, estimated to be in excess of $24,000 \mathrm{kWh}$ per person per year. The UAE, Canada, Finland, Sweden and the United States follow, with emphasis on the need for heating consumption of electricity in Scandinavia, and cooling in the UAE. When considering China's usage per capital, it does not feature in the least efficient countries on this list. This is also the case with regards to the average power per capital.

\section{Insert Tables 2 and 3 about here}

In Tables 2 and 3, we observe estimates of the electricity prices facing both households and businesses as of 2019. Within this list, we observe that countries such as Iran, Iraq and other

middle eastern nations such as Qatar present evidence of substantially reduced household charges for electricity. Germany represents the most expensive country to buy domestic electricity per kW, closely followed by Denmark, Belgium, Portugal, Jamaica and Japan. In terms of the business charges in Table 3, although rates are broadly reduced in comparison to household estimates, Denmark is the most expensive at US $\$ 0.28$ per $\mathrm{kW}$. This is closely followed by Jamaica and Costa Rica. In terms of the cheapest countries in which to buy electricity, Venezuela, Libya and Ethiopia represent the cheapest countries in which to run potential cryptocurrency mining operations.

In each country, a substantial number of mining companies have harnessed a large amount of network hash power in their mining efforts, creating a more centralised structure of the mining process. The three countries with the largest production of Bitcoin include:

1. China: which mines the most bitcoins of any nation and has been driven, in part, by cheaper electricity in comparison to international counterparts. Chinese Bitcoin miners have gained an advantage by capturing a large percentage of Bitcoin's hash power. China is home to many of the top Bitcoin mining companies such as F2Pool, AntPool, BTCC, and BW. It's estimated that these mining pools own somewhere around $60 \%$ of Bitcoins hash power, meaning they mine about $60 \%$ of all new Bitcoins. 
2. Czech Republic: accounts for approximately $10 \%$ of all mining and is home to Slush Pool, which was the first mining pool and currently mines about $11 \%$ of all blocks. Slush is probably one of the best and most popular mining pools despite not being one of the largest.

3. Iceland: accounts for $2 \%$ of cryptocurrency mining. The new industry's relatively sudden growth has been raising concerns for its environmental impact. Iceland's energy comes from hydroelectric dams and geothermal power plants, creating electricity without carbon emissions. It has been the relatively cheap, and abundant amounts of energy that have attracted multiple companies to Iceland.

4. Japan: accounts for approximately $2 \%$ of mining, driven by cheap electricity and low setup fees, both of which are a substantial advantage for venture businesses. There has been a large drive for Japanese companies setting up cryptocurrency mining processes both at home and abroad. Japanese companies moving into the business in anticipation of future growth. For example, DMM.com, has set up Japan's largest cryptocurrency mining operation in the central city of Kanazawa, while GMO Internet has one in Scandinavia.

5. Russia: accounts for $10 \%$ of international mining. Russia as a whole currently mines onetenth of the world's bitcoin production. RMC previously raised $\$ 43$ million in an initial coin offering (ICO) in 2017, which was identified as the largest Russian ICO at the time.

6. Georgia: accounts for approximately $2 \%$ of Bitcoin mining and is home to a company known as BitFury who acts as one of the largest players in the Bitcoin mining business segment, known particularly for their role in the development and sales of efficiency streaming hardware to Bitcoin users and businesses. Bitfury is one of leading full service Blockchain technology companies and one of the largest private infrastructure providers in the Blockchain ecosystem. In late 2016, the company became famous as they were estimated to be mining approximately $15 \%$ of all Bitcoins in the world.

Within these companies, there are a number of substantial mining pools. A mining pool is a joint group of cryptocurrency miners who combine their computational resources over a network. Individually, participants in a mining pool contribute their processing power toward the effort of finding a block. If the pool is successful in these efforts and is rewarded with cryptocurrency tokens as a result, the mining pool divides up these rewards to individuals who contributed according to the proportion of each individual's processing power or work relative to the whole group. In some cases, individual miners must show proof of work in order to receive their rewards. There are broadly three types of mining pools: 1) Proportional mining pools are among the most common. In this type of pool, miners contributing to the pool's processing power receive shares up until the point at which the pool succeeds in finding a block. After that, miners receive rewards proportional to the number of shares they hold; 2) Pay-per-share pools operate somewhat similarly in that each miner receives shares for his or her contribution. However, these pools provide instant payouts regardless of when the block is found. A miner contributing to this type of pool can exchange 
shares for proportional payout at any time; and 3) Peer-to-peer mining pools aim to prevent the pool structure from becoming centralised. As such, they integrate a separate blockchain related to the pool itself and designed to prevent the operators of the pool from cheating as well as the pool itself from failing due to a single central issue.

1. Poolin: is a public pool which mines about $18 \%$ of all blocks. They are based in China, but have a website fully available in English.

2. F2pool: is based in China. It mines about $17 \%$ of all blocks.

3. BTC.com: is a public mining pool that can be joined and mines $15 \%$ of all block.

4. Antpool: is a mining pool based in China and owned by BitMain. Antpool mines about $11 \%$ of all blocks.

5. ViaBTC: is a relatively new mining pool. It is targeted towards Chinese miners and mines about $9 \%$ of all blocks.

6. 1Hash \& 58coin: This is a Chinese pool made from two pools: 1 THash and 58 coin.

7. Slush Pool: was the first mining pool and currently mines about $11 \%$ of all blocks. Slush is probably one of the best and most popular mining pools despite not being one of the largest.

8. BTC.top: is a private pool and cannot be joined. It mines about $7 \%$ of all blocks.

9. Bitfury: is a private pool that cannot be joined. Bitfury currently mines about $3.5 \%$ of all blocks.

While success in individual mining grants lead to complete ownership of the reward, the probability of achieving success is very low because of high power and resource requirements. Further, due to the increasing difficulty of mining in recent years as popularity of these digital currencies has grown, mining is often not a profitable venture for individuals. The costs associated with expensive hardware necessary to be a competitive miner as well as electricity oftentimes outweigh the potential rewards. The benefits of mining pools are found within a number of key characteristics. First, they require less of each individual participant in terms of hardware and electricity costs, thereby increasing the chances of profitability. Whereas an individual miner might stand little chance of successfully finding a block and receiving a mining reward, a mining pool dramatically improves the success rate as the cumulative effort leads to better chances of finding a block, though the joint effort comes at the cost of shared reward. However, by taking part in a mining pool, individuals give up some of their autonomy in the mining process. They are typically bound by rules established within the pool while they are further required to share any potential rewards, which reduces profits in comparison to working alone. 


\section{What are the main identified issues to date?}

\subsection{Do cryptocurrency miners take advantage of developing regions?}

As we have been developing, cryptocurrency miners seek low cost electricity and permissive policy environments, which can also unfortunately create environmental hazards and substantial impacts upon local consumers without producing any benefit for communities. The energy needs of these miners means that mining is in fact quite mobile. China has been a dominant force in the cryptocurrency industry, acting as a home to the world's largest Bitcoin mining companies. Regions such as the Xinjiang or Sichuan possess substantial surplus energy which can be made available to these mobile mining operations. Since 2018, China has however begun to exert regulatory pressure on provincial governments to encourage the closure of crypto mining operations and has withdrawn incentivised taxation offers. Further, China has consistently attempted to enact financial regulations on cryptocurrencies. Notably, The People's Bank of China, China's central bank, implemented measures prohibiting domestic Bitcoin exchanges and banning the practice of raising public funds for the development new cryptocurrencies, while China's financial regulatory measures have been found to correlate with depreciation in Bitcoin's value. Due to these issues and similar problems in North America and Western Europe, these operators have been continuing to explicitly seek out countries with looser regulatory environments and physical environments that favour the cost of crypto-mining production.

Crypto-mining facilities potentially subsidise the development of renewable energy resources by seeking the cheapest resource, optimising consumption value. In 2017, 80\% of China's Bitcoin mining operations were based in Sichuan, a province that generates approximately $90 \%$ of its energy production from renewable resources, thereby accounting for $43 \%$ of global Bitcoin mining operations. The profitability of cryptocurrency mining is dependent on the currency's market value in concurrence with the price of electricity. The most efficient mining operations are those that can operate at the lowest cost by obtaining the cheapest electricity capable of supporting extreme consumption. As a result, miners seek cheap electricity markets while benefiting from policy environments that do not regulate the ways in which electricity can be consumed. This can manifest in a number of quite unusual outcomes. With regards to countries without substantial asset resorts, the Democratic Republic of Congo for example, has been linked with a number of substantial projects that could help to protect children there from forced labour.

One particular project has the ambition to provide global manufacturers of high-tech devices like smartphones with a guarantee that cobalt used in lithium-ion batteries was not mined by children which has been an incredibly broad issues associated with cobalt development in the country. The Democratic Republic of Congo is reported to possess in excess of half of the world's cobalt resources, which will become ever more valuable as companies attempt to develop electric cars. Other substantial issues have been identified in Venezuela, where hyperinflation has prompted 
dramatic shortages of basic necessities and food, bitcoin and other cryptocurrencies could help ease the strain. Given its global usage and the relative ease of cross-border payments and transfers, cryptocurrency has been a viable alternative to an increasingly problematic local fiat money for many Venezuelan citizens. The Petro (PTR) has its origin in the idea of president Hugo Chavez of a strong currency backed by raw materials. The blockchain allows the transfer of value and information, without third parties, they provide the tools to successfully face the challenge of creating platforms and financial instruments that are transparent, efficient and inclusive. Petro was aimed to be a sovereign crypto asset backed by oil assets and issued by the Venezuelan State as a spearhead for the development of an independent, transparent and open digital economy open to the direct participation of citizens. It is also aimed to serve as a platform for the growth of a fairer financial system that contributes to development, autonomy and trade between emerging economies. Venezuelan oil assets will be used to promote the adoption of crypto assets and technologies based on the country's blockchain. The ambition of the State is to promote and encourage the use of Petro with a view to consolidating it as an investment option, savings mechanism and means of exchange with State services, industry, commerce, and citizens in general. Petro aspired to be an instrument for to develop Venezuela's economic stability and financial independence, while also providing an opportunity to create a freer, more balanced and fairer international financial system.

Further, Haiti, a country that has been still reeling from natural disaster, and possessing a gross national Income per capita of approximately $\$ 900$, have also attempted to benefit from blockchain. The Haitian government has suggested that blockchain technology could be used to record and register property transactions, voting, intellectual property and other aspects of the national bureaucracy. Proponents of blockchain believe that its further development in such regions could enhance the distribution of government services, therefore helping to provide identity services and

even help to enhance freedom of speech while counteracting corruption which has been prevalent in these jurisdictions.

\subsection{Global warming effects?}

A key element of many cryptocurrencies, including bitcoin, is that so-called miners compete to complete complex mathematical calculations to get the right to add a 'block' to the blockchain. The addition of the block stores information about a transaction, and the winning miner is rewarded for its work. The rise in cryptocurrency mining can therefore be seen as environmentally damaging in two ways. Firstly, the mining of cryptocurrency requires substantial volumes of electricity. Secondly, cryptocurrency mines are distributed in a way that enables them to take advantage of cheap electricity in countries that utilise power generation from non-renewable resources such as coal, effectively giving the industry a commercial preference towards unsustainable energy. Additionally, bitcoin mining falls outside conventional environmental regulatory frameworks designed to address traditional mining. While the physical damage on-site remains minimal, the indirect environmental 
damage these mines produce as a result of their electricity consumption remains unchecked. Similarly, bitcoin miners are not required to offset or mitigate their electricity consumption as other forms of mining or even industrial operations may be required to do. Consequently, not only do bitcoin mines use vast amounts of electricity, they are not held to any form of environmental standard for either where they source their electricity, nor are they required to mitigate the environmental damage they cause.

In a 2018 study that examined the entire chain of events that leads to the creation of Bitcoin, researchers at University of Hawaii at Manoa ${ }^{3}$ examined how the projected growth of this cryptocurrency would harm the climate. By way of comparison, the scientists compiled data on the uptake of forty different technologies ranging from dishwashers and e-books to electric power and the internet. Compiling data on the electricity consumption of the various computing systems used for Bitcoin verification at present and the emissions from electricity production in the countries of the companies that performed such computing, the authors estimated that in 2017, Bitcoin usage emitted 69 MtCO2e. They used this information to estimate the rate of uptake this cryptocurrency will see in the coming years. Based on their most conservative appraisal, the team found that the cumulative emissions from bitcoin would be enough to push global warming beyond $2 \mathrm{C}$ in 22 years. If the average rate of technology uptake is used instead, this number is closer to 16 years. To work it out, the scientists analysed the power efficiency of computers used in bitcoin mining, the location of miners around the world and the $\mathrm{CO} 2$ emissions from electricity in those countries. The finding that emissions from an expanding bitcoin could push the Earth beyond $2 \mathrm{C}$ of warming above the pre-industrial level is particularly stark given the Intergovernmental Panel on Climate Change's recent report on the impacts of such a temperature rise. The report's authors warned that to avoid the worst impacts of climate change, such as coral reef extinction and Arctic ice disappearance, warming must be limited to $1.5 \mathrm{C}$. Though bitcoin has growing rapidly in the decade since it was introduced, this growth has somewhat stagnated over the past 10 months, suggesting fears about its climate impacts may be premature. However, this research was met with some opposition. Given the decentralised nature of Bitcoin and the need to maximise economic profits, its computing verification process is likely to migrate to places where electricity is cheaper, suggesting that electricity de-carbonisation could help to mitigate Bitcoin's carbon footprint âĂ ̌̌ but only where the cost of electricity from renewable sources is cheaper than fossil fuels. One of the key arguments proposed by opponents surrounded the efficiency of the mining process. While the future growth of cryptocurrencies like bitcoin is highly unpredictable, we do know that the global electric power sector is de-carbonising and that information technologies, including cryptocurrency mining rigs, are becoming much more energy efficient

\footnotetext{
${ }^{3}$ Available at: https://www.hawaii.edu/news/article.php?aId=9588
} 


\subsection{Could Bitcoin stop hinder functionality of the internet?}

The continuing argument surrounding the benefits and complications that the development of Bitcoin and other cryptocurrencies provide has provided much substantial debate. However, at times, it has often teetered somewhat on brink of exceptionally alarmist and sensationalist accusations, such as that which accused Bitcoin of containing enough disruptive force to hinder and even stop the functionality of the internet. This accusation obtained far more credibility when in June 2018, the Bank of International Settlements released a report ${ }^{4}$ which stated that amongst a number of substantial concerns, the rapid growth of Bitcoin could generate substantial issues with regards to the functionality of the internet. One of the key elements of the report read: "To process the number of digital retail transactions currently handled by selected national retail payment systems, even under optimistic assumptions, the size of the ledger would swell well beyond the storage capacity of a typical smartphone in a matter of days, beyond that of a typical personal computer in a matter of weeks and beyond that of servers in a matter of months. But the issue goes well beyond storage capacity, and extends to processing capacity: only supercomputers could keep up with verification of the incoming transactions. The associated communication volumes could bring the internet to a halt, as millions of users exchanged files on the order of magnitude of a terabyte." This would manifest through the need for an incredible amount of computer storage for major cryptocurrencies to keep up with the speed of transaction-processing systems that are currently in place. This finding presents a major issue for the process surround the scaling-up of cryptocurrencies. Each miner is required to download and verify the history of all transactions ever made, including amount paid, payer, payee and other details. The issues then surrounds the growth of this enormous history, with every transaction more information, the ledger continues to grow substantially as time passes. As of January 2020, the size of the Bitcoin blockchain alone was 240GB. Figure 12 presents the estimated energy consumption that this represents between 2017 and 2019. Other cryptocurrencies, such as Ethereum, Litecoin and Bitcoin Cash, for example, were 181GB, 22GB, 158GB respectively. To deal with this issue, cryptocurrencies have limits on the throughput of transactions in order to keep the size and of the ledger and the time needed to verify all transactions manageable.

\section{Insert Figure 12 about here}

The disintegration of the actual processing power of cryptocurrency would manifest when considering the number of digital retail transactions currently handled by selected national retail payment systems. When considering the average computer used during the retail process, or indeed the mobile technology used for cost-efficiency throughout, one can easily understand how quickly that

\footnotetext{
${ }^{4}$ Available at: https://www.bis.org/publ/arpdf/ar2018e5.htm
} 
the size of the cryptocurrency ledger would overwhelm the storage capacity of such technology, it presents a clear example as to how the continued evolution of digital technology could actually lead to substantial issues without further technological evolution. Despite this extremely negative finding, the BIS did however add that blockchain and its associated distributed ledger technology could provide some benefits for the global financial system. It stated that the software have the potential to make the sending of cross-border payments more efficient, and with the regards to international flows could improve the exporting and importing industry.

\section{Does there exist regulatory solutions?}

There are a number of potential solutions to the problem as to how to reduce the environmental impacts sourced within the Bitcoin mining process. There are a number of schools of thought with regards to such a solution, but theory suggests that two prevail: first, policy-makers could stand aside and let the market attempt to solve the issue on its own, while secondly, the government could immediately stand in and regulate the entire market in a rigid manner should the stated issues continue to escalate.

When allowing that the market will solve these environmental issues on its own, it is assumed that the market participant will acquire information about the externalities on a voluntary basis, while then working to solve them without government involvement. Generally, such markets often become more efficient over time as they will theoretically correct government failures. The process of mining somewhat counteracts this theory. Bitcoin's blockchain system involves multiple miners competing to be first to successfully undertake verification work, where only the first successful miner will be rewarded, leading to significant delays in transaction processing times and costs. To counteract this, miners have become innovative and developed the technology that they use, but this advancement on its own is not enough. This approach remains problematic as it relies on the market naturally identifying cost driven solutions that are also environmentally beneficial. As outlined, this can work, but the most cost-effective solution will not always be an environmentally beneficial one, particularly as the cost-driven approach in the past has been for mining to occur in low cost jurisdictions like China, where the environmental costs of bitcoin mining are more pronounced. If markets identified more commercially effective means of improving efficiency this may see progress towards more environmentally efficient outcomes stall.

The alternative solution is to implement government regulation. Regulatory frameworks can help to internalise environmental costs, so that commercial-effective solutions directly take into account environmentally-effective ones. Such frameworks can introduce rules and requirements which have the effect of better controlling or mitigating the environmental impacts of cryptocurrency while they could also include conventional cap and trade schemes designed specifically for the cryptocurrency industry, to control the amount of electricity used by bitcoin mines. Alternatively (or additionally), 
incentivising the use of clean energy sources in bitcoin mining could be be further encouraged as a more environmentally conscious developments in the industry. If one country introduces onerous regulations to improve the environmental impacts of cryptocurrencies, and this comes at a commercial cost, cryptocurrency miners may move offshore to a country that does not enforce or have such regulations in place (broadly like miners did to utilise low cost electricity in China). Regulations must therefore take into account the unconventional nature of bitcoin mines and their ability to easily relocate if regulations are unfavourable. Globally coordinated efforts to regulate cryptocurrency's environmental impacts may mitigate this outcome, though present regulatory agreement and diverse policy approaches make this unlikely in the short term. However, there are many other issues that must be addressed in a regulatory construct in advance of such deep-rooted industrial concerns. There have bee many issues with the generation of fake ICOs, where energy is wasted in a manner that eventually leads to those operating the ICO simply walking away with the funds of unsuspecting investors. Such types of fraud have been exceptionally damaging for the industry at large, creating a broad opinion that cryptocurrencies have been ripe with fraud. This image was not helped as substantial rumours began, later supported by evidence that the exchanges had been largely driven by fake volumes traded. There are now developing broad fears that such interactions might have been misstated due to the widespread allegations that now exist based on the presence of fake volumes. In a recent SEC report ${ }^{5}$, Bitwise Asset Management examined exchanges for fake volume, and found that roughly $95 \%$ of reported trading volume in Bitcoin is fake or non-economic in nature. Bitwise used screen scrapers to collect live trading data from over eighty exchanges for a period of several months. The only ten exchanges that passed Bitwise's tests were Binance, Bitfinex, Coinbase, Kraken, Bitstamp, bitFlyer, Gemini, itBit, Bittrex, and Poloniex. This research compared the number of website visits to trading volume across exchanges to identify suspects that participate in faking trading volume, as indicated by disproportionately high volume relative to website visits. In all, the report utilises forty-eight cryptocurrency exchanges, focusing on monthly traffic between November 2018 and April 2019. There were nearly 800 million cryptocurrency exchange website visits in that time period, while the total reported trading volume was $\$ 1.96$ trillion, of which only $\$ 272.5$ billion appears to be real trading volume on non-volume faking exchanges. About $86 \%$ of the trading volume looks to be fake with $65 \%$ of that total real volume originating on Binance and Bitfinex, both of which have virtually no regulatory oversight. Such fake volume is found to be either the fraudulent movement of cash or those generated from washing trades as per the definition in the Bitwise Report ${ }^{6}$ who also argues that the prices on

\footnotetext{
${ }^{5}$ Available at: https://www.sec.gov/comments/sr-nysearca-2019-01/srnysearca201901-5574233-185408.pdf

6 "fake volume refers to any reported trading volume that does not reflect legitimate price discovery in the market. This includes: 1. Fraudulent Prints: This is volume that is simply printed on the tape by an exchange, with no corresponding trading taking place, or 2. Wash Trading: Wash trading occurs when a single or affiliated trader executes trades with itself." from Bitwise Report
} 
exchanges with fake volume do not influence the price of bitcoin in the real spot market.

To mitigate these continued developing issues, cryptocurrency market regulation would necessitate deep-rooted exchange regulation. Almost all foreign exchange flows through banks or currency houses where all transactions should run through an exchange that is regulated. In recent times, British banks are turning away cryptocurrency exchanges, and even closing customers' accounts for wiring to an exchange, so even if they'd prefer to be based in the UK, exchanges have to open accounts in mainland European countries such as Slovenia. Without tight regulation, they fear the funds could be used by criminals on the dark web or for money laundering. If they are part of that process, they could get fined or shut down. Exchanges should then be allowed to manage ICOs, to reduce the number of fake or fraudulent ICOs that exist. Investors would then follow Know-Your-Customer and Anti-Money Laundering processes. Many of the warnings issued by various countries also note the opportunities that cryptocurrencies create for illegal activities, such as money laundering and terrorism. Some of the countries surveyed go beyond simply warning the public and have expanded their laws on money laundering, counter-terrorism, and organized crimes to include cryptocurrency markets, and require banks and other financial institutions that facilitate such markets to conduct all the due diligence requirements imposed under such laws. For instance, Australia, Canada, and the Isle of Man recently enacted laws to bring cryptocurrency transactions and institutions that facilitate them under the ambit of money laundering and counter-terrorist financing laws. Some jurisdictions have gone even further and imposed restrictions on investments in cryptocurrencies, the extent of which varies from one jurisdiction to another. Some (Algeria, Bolivia, Morocco, Nepal, Pakistan, and Vietnam) ban any and all activities involving cryptocurrencies. Qatar and Bahrain have a slightly different approach in that they bar their citizens from engaging in any kind of activities involving cryptocurrencies locally, but allow citizens to do so outside their borders. There are also countries that, while not banning their citizens from investing in cryptocurrencies, impose indirect restrictions by barring financial institutions within their borders from facilitating transactions involving cryptocurrencies (Bangladesh, Iran, Thailand, Lithuania, Lesotho, China, and Colombia).

One of the final necessary changes would be to clean up the international tax ambiguity with regards to cryptocurrencies. Blockchains do not work without a token, and tokens need to be traded in and out of fiat (government backed currencies like the US dollar). This means there will always be a chance to profit (in fiat terms), so governments needs to clarify their stance. One of the many questions that arise from allowing investments in and the use of cryptocurrencies is the issue of taxation. In this regard the challenge appears to be how to categorise cryptocurrencies and the specific activities involving them for purposes of taxation. This matters primarily because whether gains made from mining or selling cryptocurrencies are categorised as income or capital gains invariably determines the applicable tax bracket. One, singular universal approach might warrant further investigation when analysing the variety of tax treatments for cryptocurrency. For example, 
in the UK, when using cryptocurrencies, corporations pay corporate tax, unincorporated businesses pay income tax, individuals pay capital gains tax. While in Argentina and Spain, the assets are subject to income tax, while in Denmark they are subject to income tax with the losses deducted. In Israel, they are taxed as an asset, in Bulgaria cryptocurrency is taxed as a financial asset, while in Switzerland they are taxed as foreign currency. It is very easy to see how the broad treatment of cryptocurrency can be deemed to be confusing, but also possessing many pathways through which illicit behaviour can occur once international tax treaty's and cross-border transfer legislation is also considered. Such international tax revenue could also be best served to be partially ringfenced, acting as an insurance policy for any potential environmental damage that cryptocurrencies could generate. However, such legislative behaviour would necessitate a standardisation of the international approach.

\section{Concluding Comments}

As cryptocurrencies as a financial market product continue to evolve, it is becoming more certain that innovative solutions are going to be needed to solve some substantial forthcoming issues with regards to energy usage and technological capacity. The major fuel used by these networks, due to its relatively majority-based Chinese point of origin, is coal-fired power plants, which has resulted in an extensive carbon footprint for each transaction. This raises questions about the environmental sustainability of cryptocurrencies. The participation in the validation and mining process of Bitcoin requires both special hardware and a substantial amount of energy, therefore, there is on-going carbon production. As the cryptocurrency industry grows, and the adoption of blockchain technology increases, it is increasingly important for cryptocurrencies' blockchain technology to be more environmentally conscious. By prioritising efficiency, these new cryptocurrencies also reduce their environmental impact. In doing so, the industry neatly exemplifies how improving the environmental output of an industry can be linked to enhanced productivity and effectiveness. Coal and other fossil fuels are also the largest generator of electricity for the rest of the world, and coal is a significant contributor to man-made climate change. This reliance on fossil fuels has given rise to speculation that bitcoin's energy consumption will continue to rise as it grows in popularity. This raises questions about the environmental sustainability of cryptocurrencies.

When observing estimates of the electricity prices facing both households and businesses, we observe that countries such as Iran, Iraq and other middle eastern nations such as Qatar present evidence of substantially reduced household charges for electricity. In terms of the cheapest countries in which to buy electricity, Venezuela, Libya and Ethiopia represent the cheapest countries in

which to run potential cryptocurrency mining operations. This makes such countries attractive to cryptocurrency miners. However, the political stability of some might not be feasible. Further, crypto-mining facilities potentially subsidise the development of renewable energy resources by 
seeking the cheapest resource, optimising consumption value. The profitability of cryptocurrency mining is dependent on the currency's market value in concurrence with the price of electricity. The most efficient mining operations are those that can operate at the lowest cost by obtaining the cheapest electricity capable of supporting extreme consumption. As a result, miners seek cheap electricity markets while benefiting from policy environments that do not regulate the ways in which electricity can be consumed. This can manifest in a number of quite unusual outcomes, such as those experienced in the Democratic Republic of Congo, Venezuela and Haiti. Proponents of blockchain believe that its further development in such regions could enhance the distribution of government services, therefore helping to provide identity services and even help to enhance freedom of speech while counteracting corruption which has been prevalent in these jurisdictions.

The rise in cryptocurrency mining can therefore be seen as environmentally damaging in two ways. Firstly, the mining of cryptocurrency requires substantial volumes of electricity. Secondly, cryptocurrency mines are distributed in a way that enables them to take advantage of cheap electricity in countries that utilise power generation from non-renewable resources such as coal, effectively giving the industry a commercial preference towards unsustainable energy. Additionally, bitcoin mining falls outside conventional environmental regulatory frameworks designed to address traditional mining. While the physical damage on-site remains minimal, the indirect environmental damage these mines produce as a result of their electricity consumption remains unchecked. Similarly, bitcoin miners are not required to offset or mitigate their electricity consumption as other forms of mining or even industrial operations may be required to do. Consequently, not only do bitcoin mines use vast amounts of electricity, they are not held to any form of environmental standard for either where they source their electricity, nor are they required to mitigate the environmental damage they cause. The disintegration of the actual processing power of cryptocurrency would manifest when considering the number of digital retail transactions currently handled by selected national retail payment systems. When considering the average computer used during the retail process, or indeed the mobile technology used for cost-efficiency throughout, one can easily understand how quickly that the size of the cryptocurrency ledger would overwhelm the storage capacity of such technology, it presents a clear example as to how the continued evolution of digital technology could actually lead to substantial issues without further technological evolution.

Overall, the total carbon footprint of the industry is now estimated to have surpassed that of many large industrial nations. This chapter has investigated the multiple knock-on effects and consequential behaviour of this rapid growth in energy usage, such as an increase in global temperature, the growth of mining companies who have targeted third world infrastructures, and the complete shutdown of the internet as we know it. Considering the evidence provided, we encourage investors not to ignore these environmentalism matters, particularly due to the substantial electricity consumption from coal in countries such as China. Further investigation of these issues are exceptionally important, as should they continue to be made without fair supporting analysis, it 
could be considered to be an unfair attack on this developing industry. However, should such problems continue to transpire with evidence provided, it is of the utmost importance that regulators, policy-makers and governments alike take appropriate action.

\section{Bibliography}

Akhtaruzzaman, M., A. Sensoy, and S. Corbet (2019). The influence of bitcoin on portfolio diversification and design. Finance Research Letters, 101344.

Akyildirim, E., S. Corbet, P. Katsiampa, N. Kellard, and A. Sensoy (2019). The development of bitcoin futures: Exploring the interactions between cryptocurrency derivatives. Finance Research Letters, forthcoming.

Bariviera, A. F. (2017). The inefficiency of bitcoin revisited: A dynamic approach. Economics Letters 161, 1-4.

Baur, D. G., T. Dimpfl, and K. Kuck (2018). Bitcoin, gold and the us dollar-a replication and extension. Finance Research Letters 25, 103-110.

Corbet, S., D. J. Cumming, B. M. Lucey, M. Peat, and S. A. Vigne (2019). The destabilising effects of cryptocurrency cybercriminality. Economics Letters, 108741.

Corbet, S., C. Larkin, B. Lucey, A. Meegan, and L. Yarovaya (2020a). Cryptocurrency reaction to fomc announcements: Evidence of heterogeneity based on blockchain stack position. Journal of Financial Stability 46, 100706.

Corbet, S., C. Larkin, B. M. Lucey, A. Meegan, and L. Yarovaya (2020b). The impact of macroeconomic news on bitcoin returns. The European Journal of Finance, 1-21.

Corbet, S., B. Lucey, M. Peat, and S. Vigne (2018). Bitcoin futures: What use are they? Economics Letters 172, $23-27$.

Corbet, S., B. M. Lucey, A. Urquhart, and L. Yarovaya (2019). Cryptocurrencies as a financial asset: A systematic analysis. International Review of Financial Analysis 62, 182-199.

Corbet, S., A. Meegan, C. Larkin, B. Lucey, and L. Yarovaya (2018). Exploring the dynamic relationships between cryptocurrencies and other financial assets. Economics Letters 165, 28-34.

Easley, D., M. O'Hara, and S. Basu (2019). From mining to markets: The evolution of bitcoin transaction fees. Journal of Financial Economics, forthcoming.

Ekinci, C., E. Akyildirim, and S. Corbet (2019). Analysing the dynamic influence of us macroeconomic news releases on turkish stock markets. Finance Research Letters 31, 155-164.

Foley, S., J. R. Karlsen, and T. J. Putnins (2019). Sex, drugs, and bitcoin: How much illegal activity is financed through cryptocurrencies? The Review of Financial Studies 32(5), 1789-1853.

Greenberg, P. and D. Bugden (2019). Energy consumption boomtowns in the united states: Community responses to a cryptocurrency boom. Energy research Social Science 50, 162-167.

Katsiampa, P., S. Corbet, and B. Lucey (2019). Volatility spillover effects in leading cryptocurrencies: A BEKKMGARCH analysis. Finance Research Letters, 29, 68-74. 
Krause, M. J. and T. Tolaymat (2018). Quantification of energy and carbon costs for mining cryptocurrencies. Nature Sustainability 1(11), 711.

Li, J., N. Li, H. Cui, and Z. Wu (2019). Energy consumption of cryptocurrency mining: A study of electricity consumption in mining cryptocurrencies. Energy 168, 160-168.

Li, J., N. Li, J. Peng, H. Cui, and Z. Wu (2019). Energy consumption of cryptocurrency mining: A study of electricity consumption in mining cryptocurrencies. Energy 168, 160-168.

Mensi, W., Y.-J. Lee, K. H. Al-Yahyaee, A. Sensoy, and S.-M. Yoon (2019). Intraday downward/upward multifractality and long memory in Bitcoin and Ethereum markets: An asymmetric multifractal detrended fluctuation analysis. Finance Research Letters 31, 19-25.

Mora, C., R. L. Rollins, K. Taladay, M. B. Kantar, M. K. Chock, M. Shimada, and E. C. Franklin (2018). Bitcoin emissions alone could push global warming above 2c. Nature Climate Change 8(11), 931.

O'Riordan, T. (1985). Research policy and review 6. future directions for environmental policy. Environment and Planning A 17(11), 1431-1446.

Sensoy, A. (2019). The inefficiency of Bitcoin revisited: A high-frequency analysis with alternative currencies. Finance Research Letters, 28, 68-73.

Stoll, C., L. KlaaBen, and U. Gallersdörfer (2019). The carbon footprint of bitcoin. Available at SSRN 3335781.

Truby, J. (2018). Decarbonizing bitcoin: Law and policy choices for reducing the energy consumption of blockchain technologies and digital currencies. Energy research Social Science 44, 399-410.

Urquhart, A. (2017). Price clustering in Bitcoin. Economics letters 159, 145-148. 
Figure 1: The Changing Characteristics of Bitcoin, 2010-2019
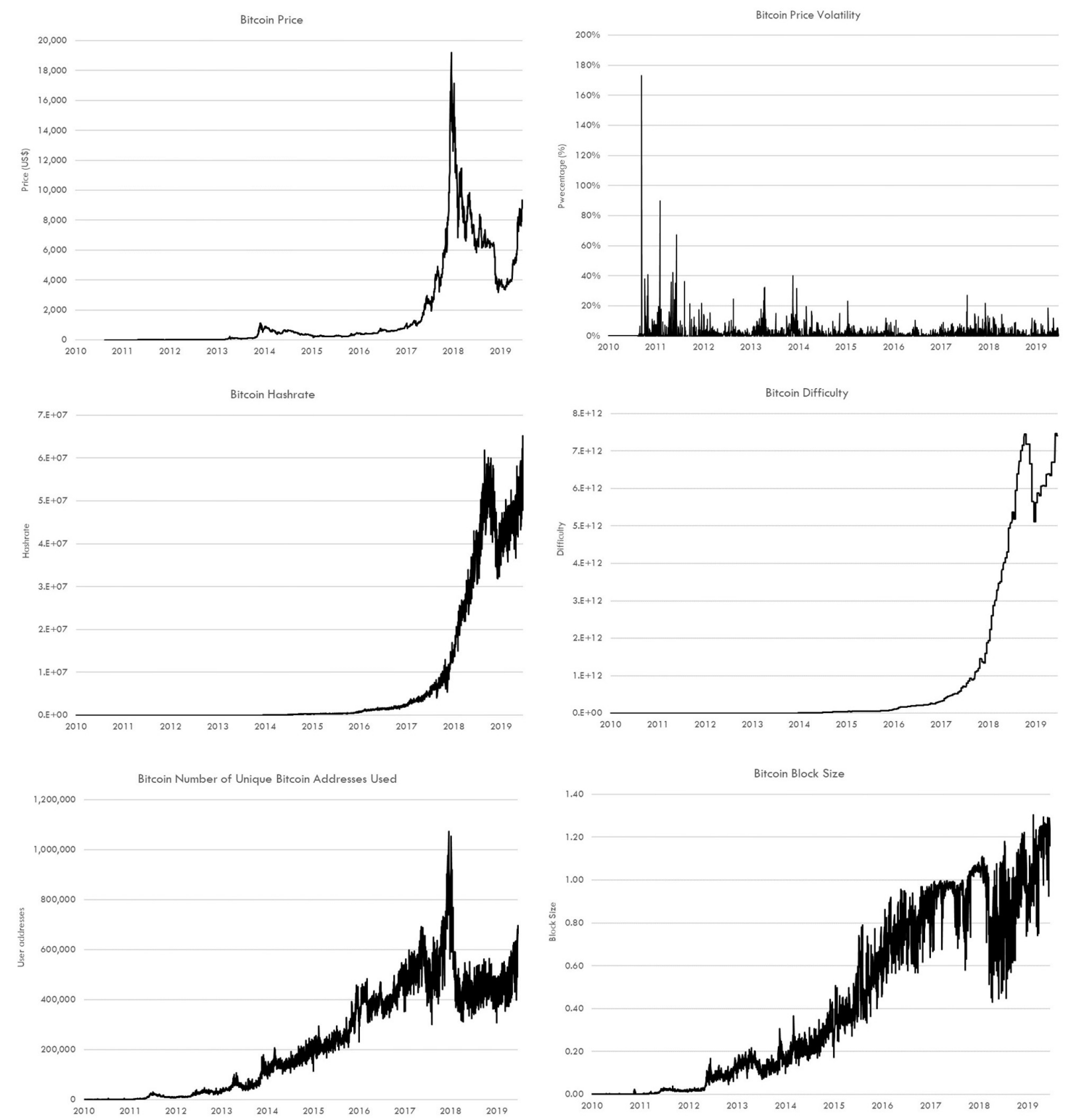

Note: The top two figures represent the price and volatility of Bitcoin between 2010 and 2019. The middle pair of figures presents the hashrate and mining difficulty respectively. The bottom figures represents the number of unique addresses used to mine Bitcoin and the block size respectively. 
Figure 2: Bitcoins in circulation

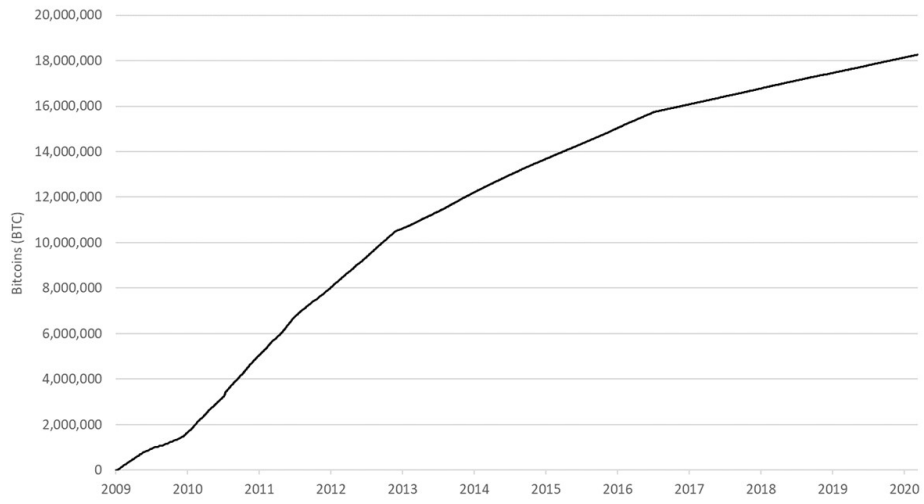

Note: The above figure presents the total number of bitcoins that have already been mined; in other words, the current supply of bitcoins on the network. The data is correct as of January 2020.

\section{Figure 3: USD (\$) Exchange Trade Volume}

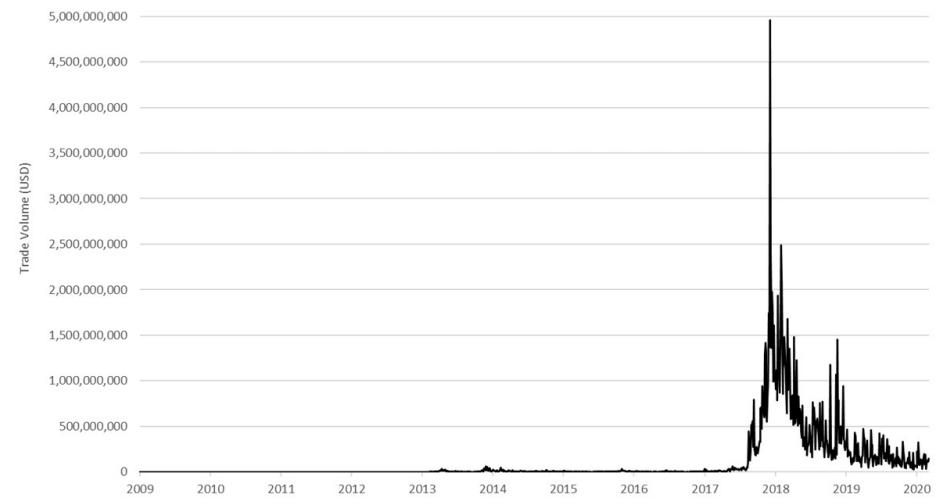

Note: The above figure presents the total USD (\$) value of trading volume on major bitcoin exchanges. The data is correct as of January 2020. 
Figure 4: Blockchain size and the average block size

a) Blockchain size

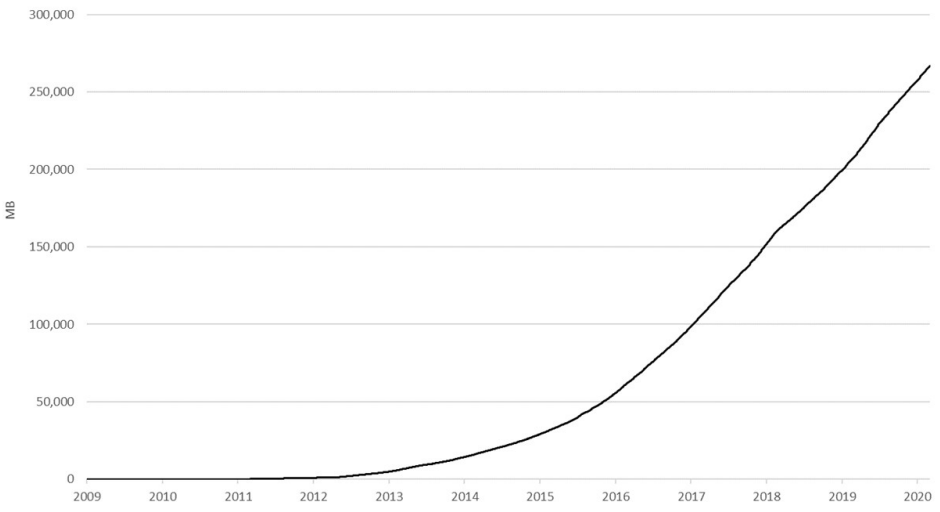

b) average block size

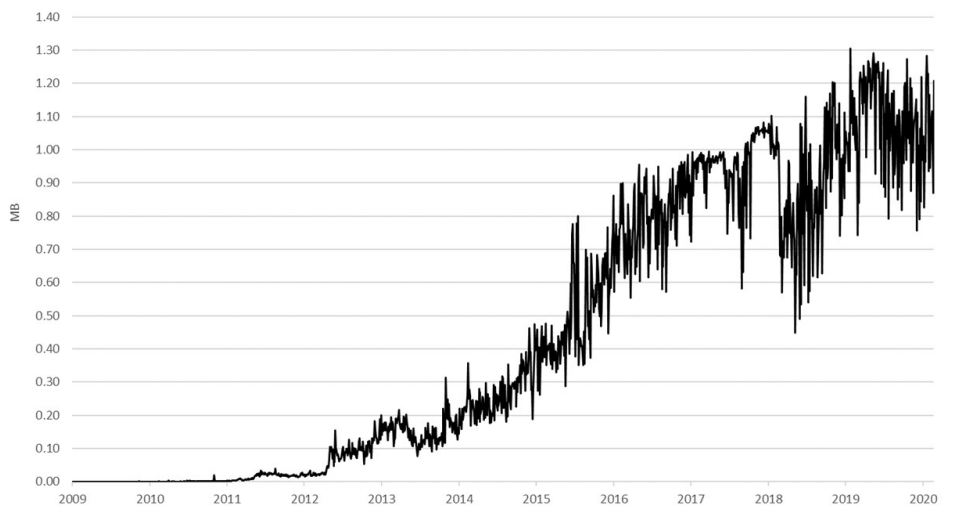

Note: The above figures represent the the total size of all block headers and transactions and the average block size in MB respectively. The data is correct as of January 2020. 
Figure 5: Average Number Of Transactions Per Block, Median Confirmation Time and Miners Revenue

a) Average Number Of Transactions Per Block

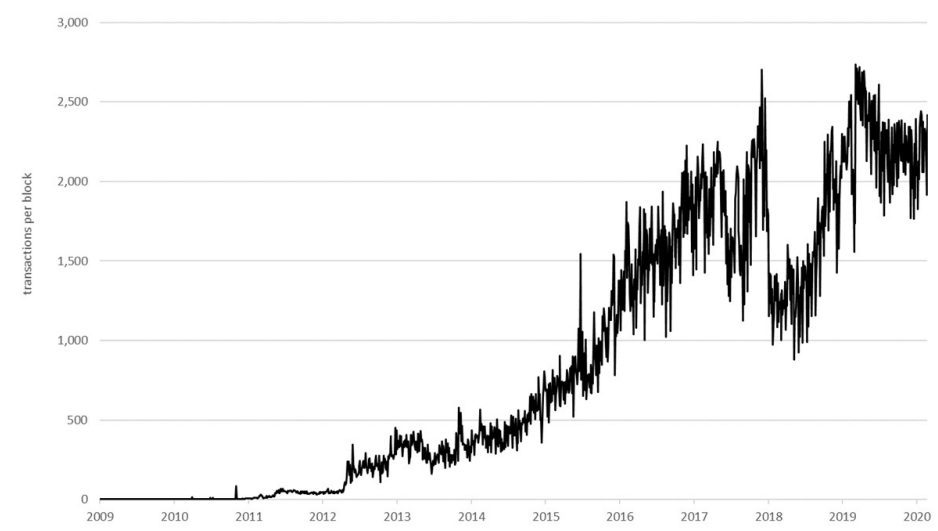

b) Median Confirmation Time

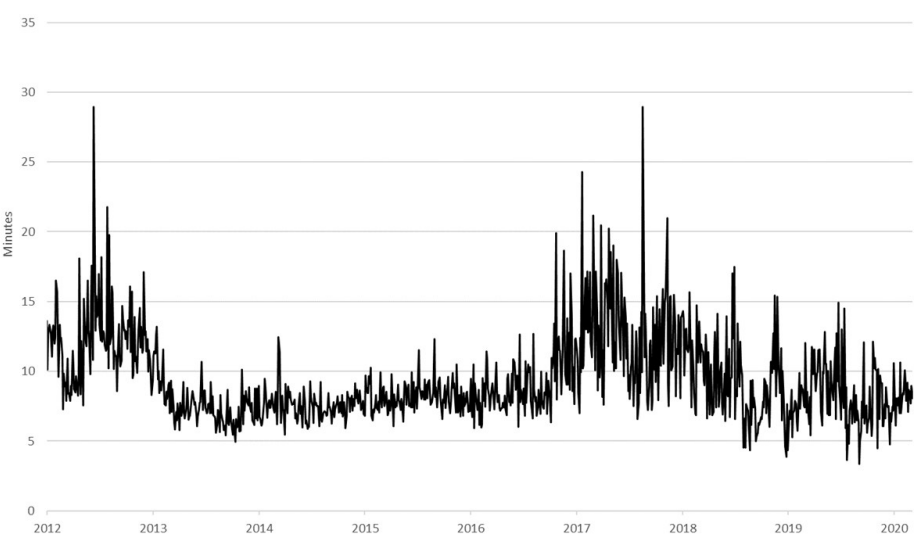

c) Miners Revenue

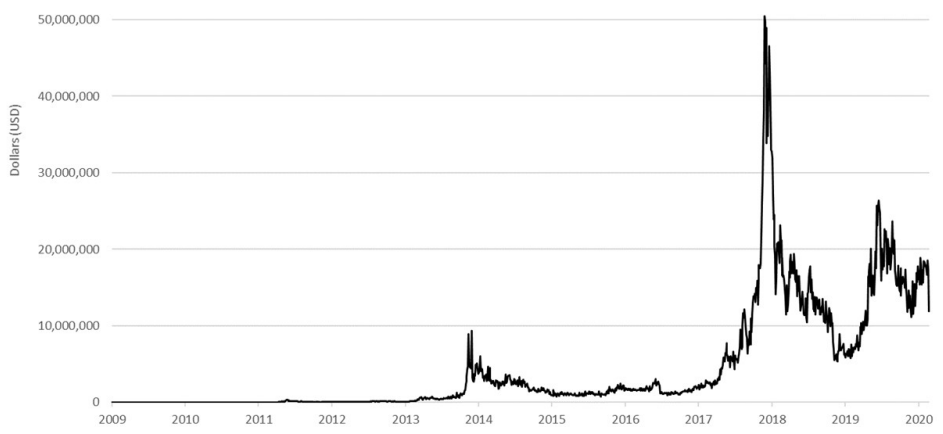

Note: The above figure presents the the average number of transactions per block, the median time for a transaction to be accepted into a mined block and added to the public ledger (note: only includes transactions with miner fees) and finally, the total value of Coinbase block rewards and transaction fees paid to miners. The data is correct as of January 2020. 
Figure 6: Total Transaction Fees, Total Transaction Fees in USD, Cost as a \% of Transaction Volume and cost per Transaction

a) Total Transaction Fees

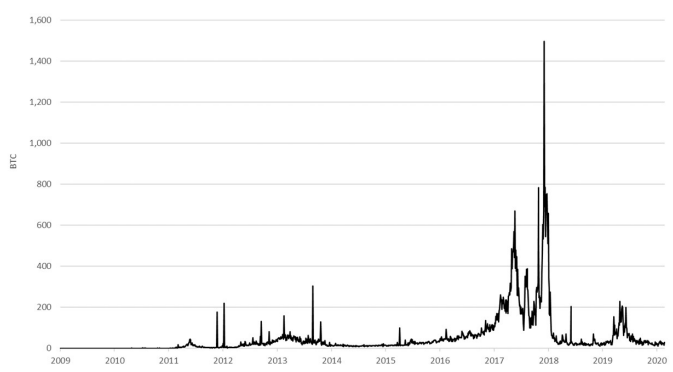

c) Cost as a \% of Transaction Volume

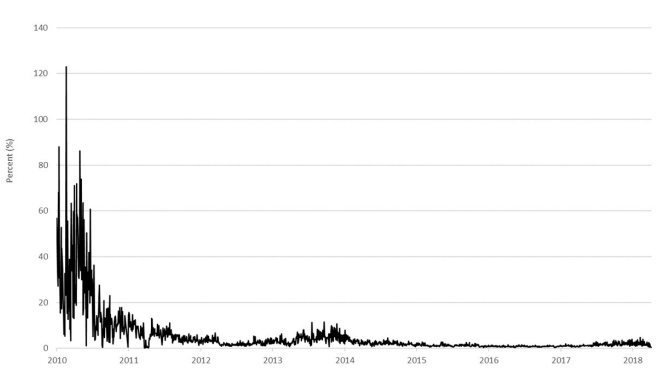

b) Total Transaction Fees in USD

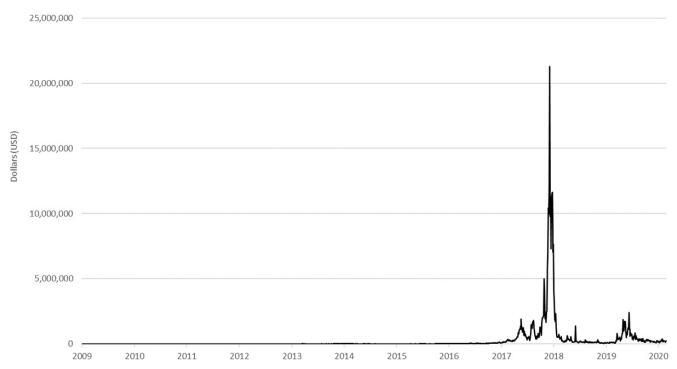

d) Cost per Transaction

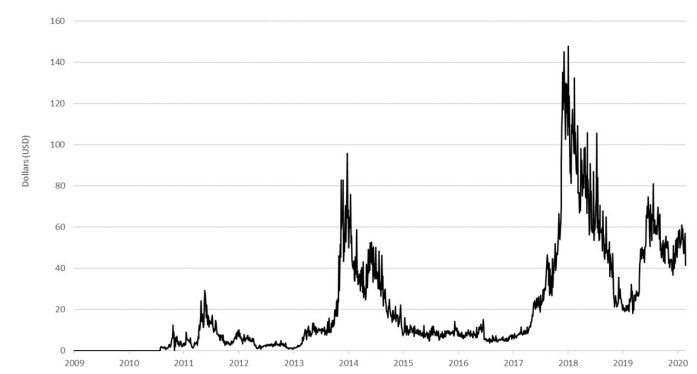

Note: The above figure presents the total value of all transaction fees paid to miners (not including the Coinbase value of block rewards), the total value of all transaction fees paid to miners (not including the Coinbase value of block rewards), miners revenue as percentage of the transaction volume and miners revenue divided by the number of transactions. The data is correct as of January 2020. 
Figure 7: Number Of Unique Addresses Used, Confirmed Transactions Per Day, Total Number of Transactions and the Transaction Rate

a) Number Of Unique Addresses Used

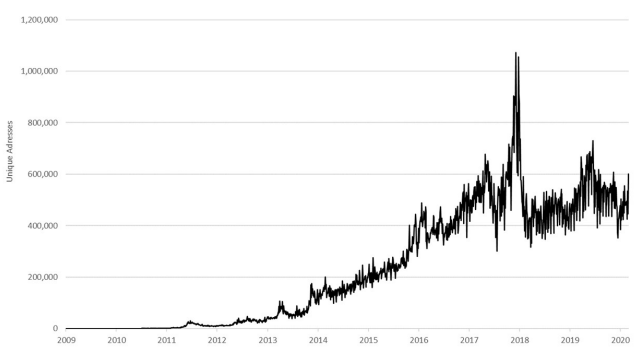

c) Total Number of Transactions

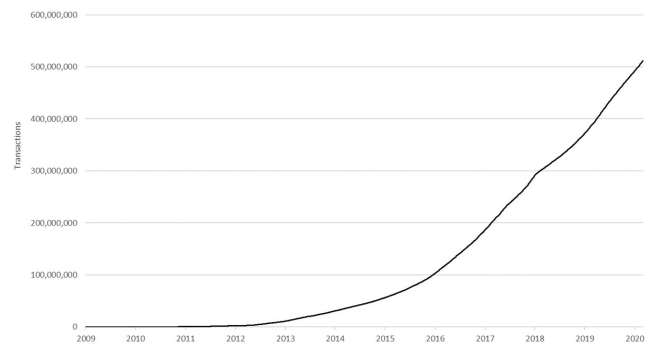

b) Confirmed Transactions Per Day

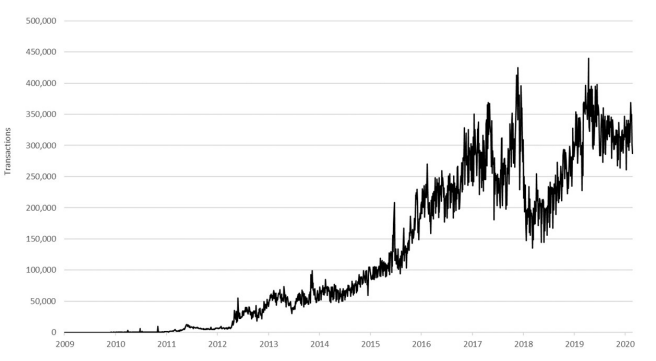

d) Transaction Rate

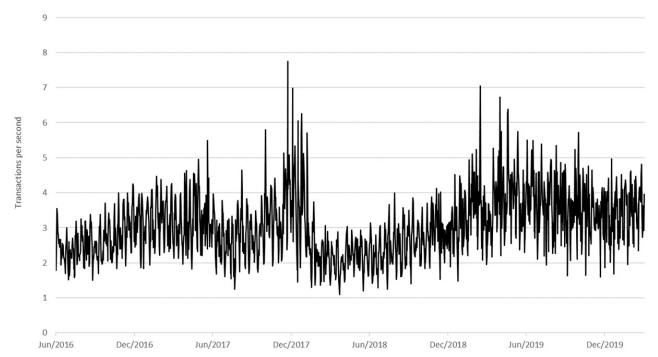

Note: The above figure presents the total number of unique addresses used on the Bitcoin blockchain, the number of daily confirmed Bitcoin transactions, the total number of transactions and the number of Bitcoin transactions added to the mempool per second. The data is correct as of January 2020. 
Figure 8: Number of Unspent Transaction Outputs and the Mempool Size

a) Number of Unspent Transaction Outputs

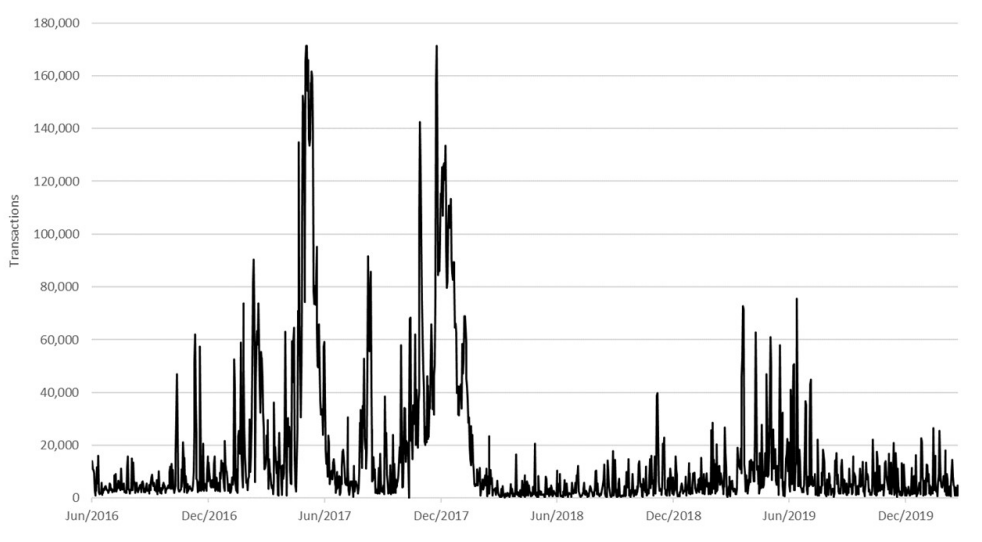

b) Mempool Size

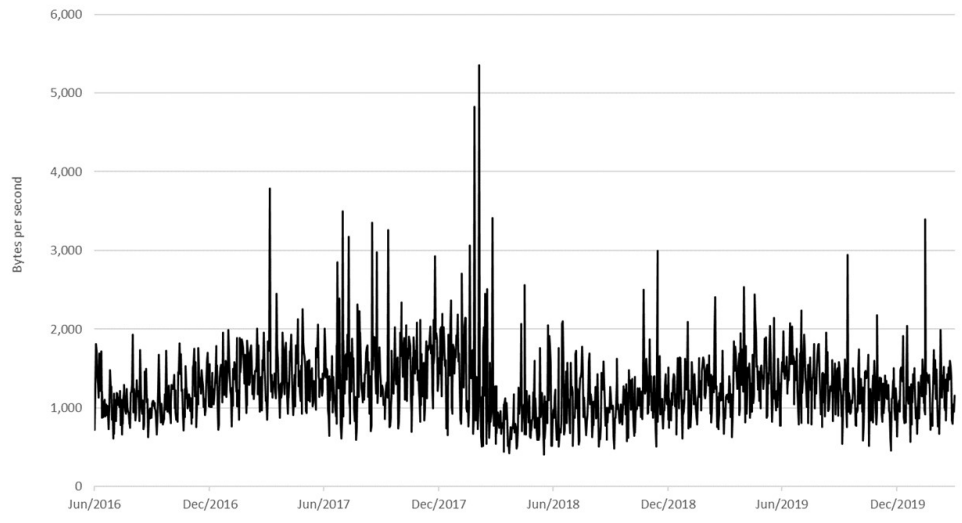

Note: The above figure presents the number of unspent Bitcoin transactions outputs, also known as the UTXO set size and the aggregate size of transactions waiting to be confirmed. The data is correct as of January 2020 
Figure 9: Number of Unspent Transaction Outputs, Number of Transactions Excluding Popular Addresses and the Output Value

a) Number of Unspent Transaction Outputs

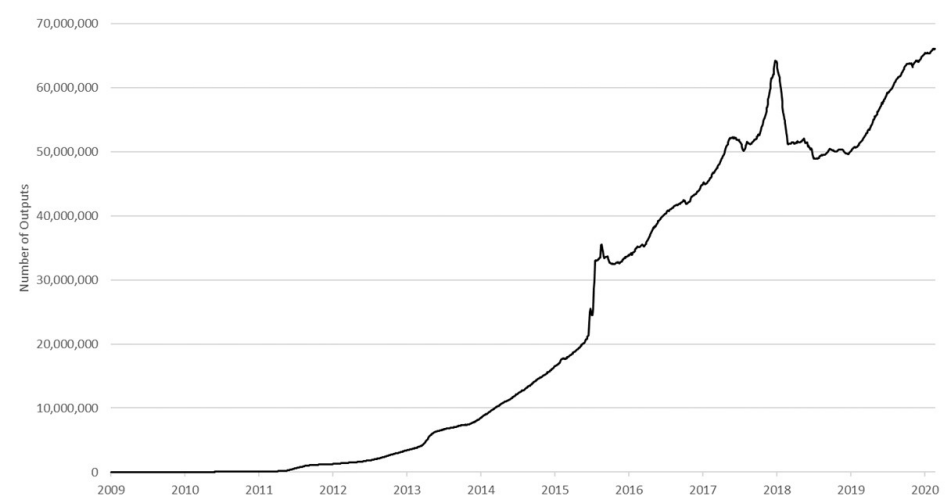

b) Number of Unspent Transaction Outputs

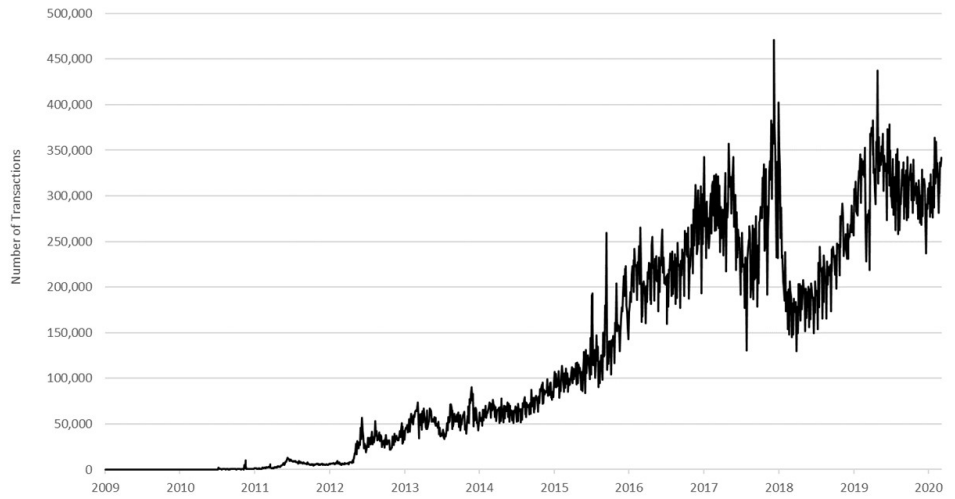

c) Output Value

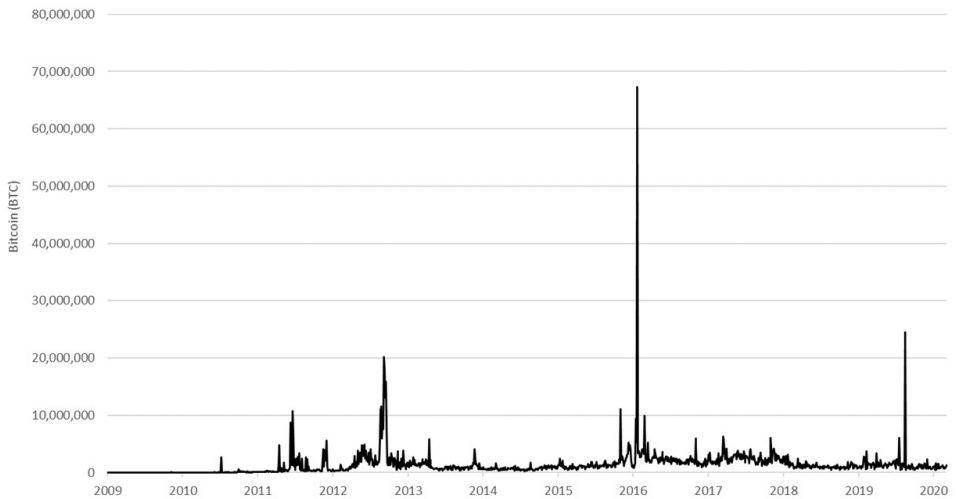

Note: The above figure presents the number of unspent Bitcoin transactions outputs, also known as the UTXO set size, the total number of Bitcoin transactions, excluding those involving any of the network's 100 most popular addresses and the total value of all transaction outputs per day (includes biylns returned to the sender as change). The data is correct as of January 2020. 
Figure 10: Estimated Transaction Value and the Estimated USD Transaction Value

a) Estimated Transaction Value

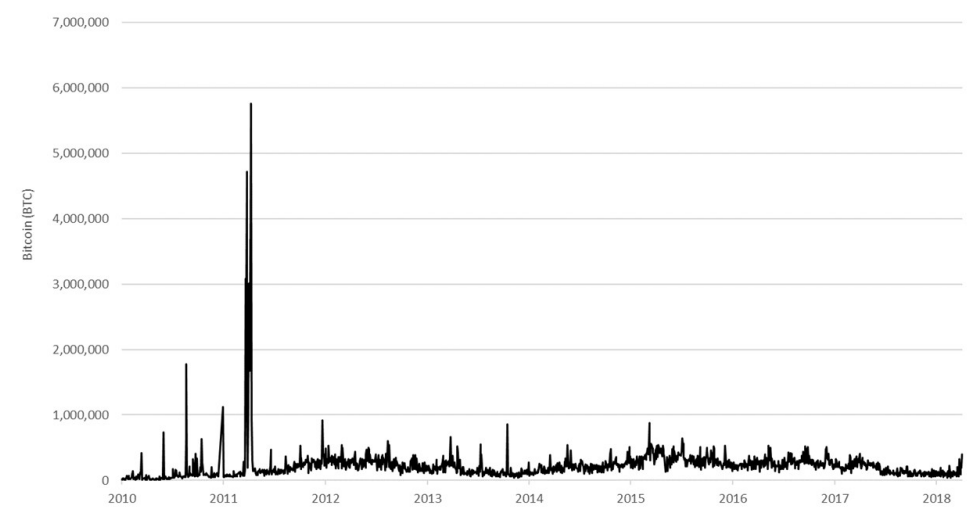

b) Estimated USD Transaction Value

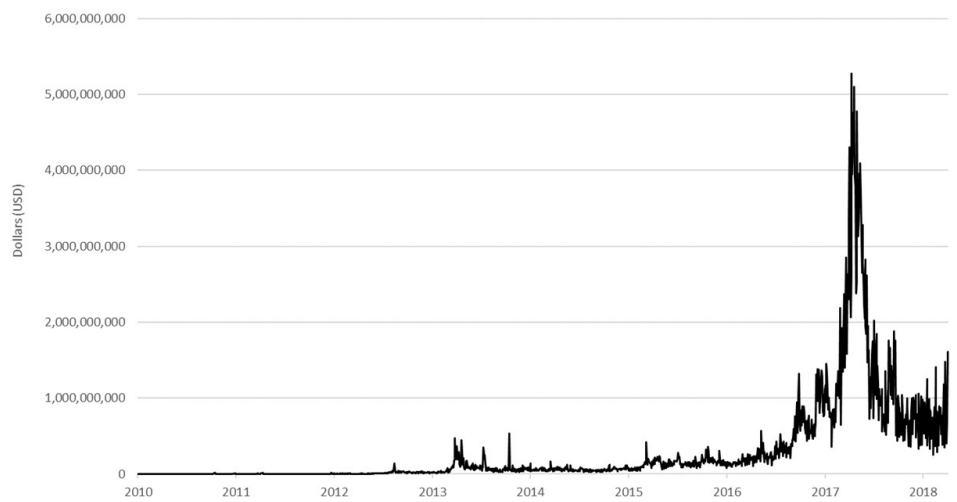

Note: The above figure presents the total estimated value of transactions on the Bitcoin blockchain (does not include coins returned to sender as change), and the Estimated Transaction Value in USD value. The data is correct as of January 2020. 
Figure 11: Blockchain Wallet Users

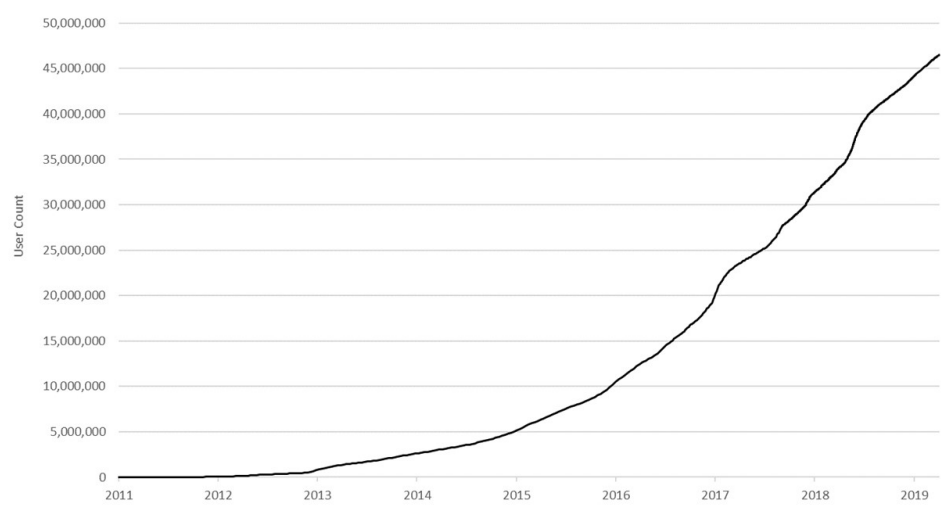

Note: The above figure presents the total number of blockchain wallet users. The data is correct as of January 2020.

Figure 12: Bitcoin Energy Consumption

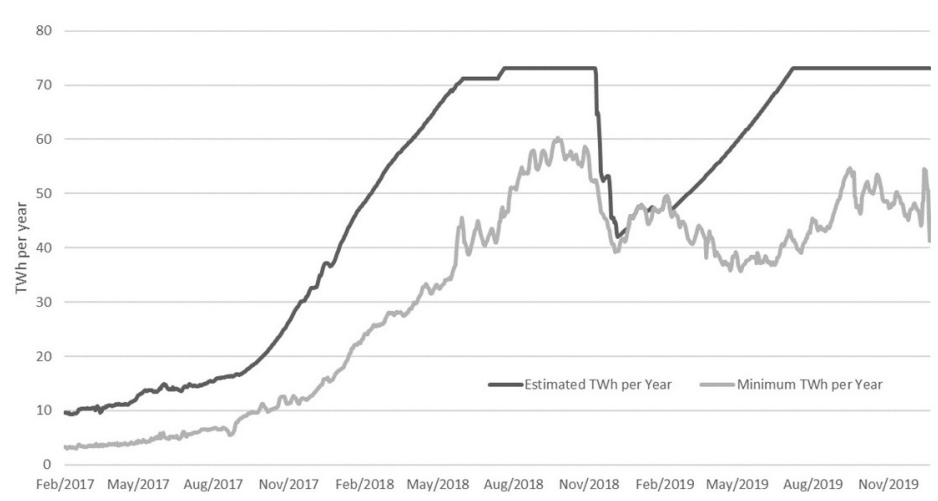

Note: The above data was obtained from https://digiconomist.net/bitcoin-energy-consumption 
Table 1: International estimates of electricity consumption, as of 2017

\begin{tabular}{|c|c|c|c|c|c|c|}
\hline Rank & Country & $\begin{array}{l}\text { Electricity consump- } \\
\text { tion (per million kW } \\
\mathrm{h} / \mathrm{yr} \text { ) }\end{array}$ & $\begin{array}{l}\text { Average electrical en- } \\
\text { ergy per capita (kWh } \\
\text { per person per year) }\end{array}$ & $\begin{array}{l}\text { Average } \\
\text { capita } \\
\text { person) }\end{array}$ & $\begin{array}{l}\text { power } \\
\text { (watts }\end{array}$ & $\begin{array}{l}\text { per } \\
\text { per }\end{array}$ \\
\hline 1 & China & $6,310,000$ & 4,475 & 510 & & \\
\hline 2 & United States & $3,911,000$ & 12,071 & 1,377 & & \\
\hline 3 & India & $1,547,000$ & 1,181 & 260 & & \\
\hline 4 & Russia & $1,065,000$ & 7,481 & 854 & & \\
\hline 5 & Japan & 934,000 & 7,371 & 841 & & \\
\hline 6 & Germany & 533,000 & 6,602 & 753 & & \\
\hline 7 & Canada & 528,000 & 14,930 & 1,704 & & \\
\hline 8 & Brazil & 518,000 & 2,516 & 287 & & \\
\hline 9 & South Korea & 495,000 & 9,720 & 1,109 & & \\
\hline 10 & France & 431,000 & 6,448 & 736 & & \\
\hline 11 & UK & 309,000 & 4,795 & 547 & & \\
\hline 12 & Italy & 291,000 & 4,692 & 535 & & \\
\hline 13 & Saudi Arabia & 272,000 & 9,658 & 1,102 & & \\
\hline 14 & Taiwan & 249,500 & 10,632 & 1,213 & & \\
\hline 15 & Mexico & 238,000 & 1,932 & 220 & & \\
\hline 16 & Spain & 234,000 & 4,818 & 550 & & \\
\hline 17 & Australia & 224,000 & 9,742 & 1,112 & & \\
\hline 18 & Indonesia & 221,070 & 1,058 & 117 & & \\
\hline 19 & Iran & 218,000 & 2,632 & 300 & & \\
\hline 20 & South Africa & 112,000 & 3,904 & 445 & & \\
\hline 21 & Turkey & 347,400 & 2,578 & 294 & & \\
\hline 22 & Thailand & 264,000 & 2,404 & 274 & & \\
\hline 23 & Egypt & 143,000 & 1,510 & 172 & & \\
\hline 24 & Ukraine & 143,000 & 3,234 & 369 & & \\
\hline 25 & Poland & 142,000 & 3,686 & 420 & & \\
\hline 26 & Malaysia & 131,000 & 4,232 & 483 & & \\
\hline 27 & Sweden & 127,000 & 12,853 & 1,467 & & \\
\hline 28 & Norway & 126,400 & 24,006 & 2,740 & & \\
\hline 29 & Vietnam & 125,000 & 1,312 & 149 & & \\
\hline 30 & Argentina & 116,000 & 2,643 & 301 & & \\
\hline 31 & Netherlands & 108,000 & 6,346 & 724 & & \\
\hline 32 & UAE & 96,000 & 16,195 & 1,848 & & \\
\hline 33 & Philippines & 94,370 & 885 & 101 & & \\
\hline 34 & Kazakhstan & 91,000 & 4,956 & 565 & & \\
\hline 35 & Pakistan & 82,000 & 471 & 50 & & \\
\hline 36 & Finland & 81,000 & 14,732 & 1,681 & & \\
\hline 37 & Belgium & 81,000 & 7,099 & 810 & & \\
\hline 38 & Venezuela & 78,000 & 2,523 & 288 & & \\
\hline 39 & Austria & 69,750 & 8,006 & 913 & & \\
\hline 40 & Chile & 66,000 & 3,739 & 426 & & \\
\hline
\end{tabular}

Note: Data obtained from https://www.cia.gov/index.html 
Table 2: Electricity prices for households as of 2019 (per kW)

\begin{tabular}{llllllll}
\hline \hline Iran & $\$ 0.01$ & India & $\$ 0.08$ & Namibia & $\$ 0.13$ & Uganda & $\$ 0.20$ \\
Burma & $\$ 0.03$ & UAE & $\$ 0.08$ & Colombia & $\$ 0.14$ & Finland & $\$ 0.20$ \\
Iraq & $\$ 0.03$ & Sri Lanka & $\$ 0.08$ & Hong Kong & $\$ 0.15$ & France & $\$ 0.20$ \\
Zambia & $\$ 0.03$ & Vietnam & $\$ 0.08$ & USA & $\$ 0.15$ & Philippines & $\$ 0.20$ \\
Egypt & $\$ 0.03$ & Lebanon & $\$ 0.08$ & Cambodia & $\$ 0.15$ & Peru & $\$ 0.20$ \\
Qatar & $\$ 0.03$ & Taiwan & $\$ 0.09$ & Macao & $\$ 0.15$ & Greece & $\$ 0.20$ \\
Algeria & $\$ 0.04$ & Turkey & $\$ 0.09$ & Lithuania & $\$ 0.15$ & New Zealand & $\$ 0.21$ \\
Kazakhstan & $\$ 0.04$ & Argentina & $\$ 0.09$ & Iceland & $\$ 0.15$ & Kenya & $\$ 0.22$ \\
Azerbaijan & $\$ 0.04$ & Botswana & $\$ 0.09$ & Malta & $\$ 0.15$ & Switzerland & $\$ 0.22$ \\
Afghanistan & $\$ 0.05$ & Serbia & $\$ 0.09$ & Honduras & $\$ 0.16$ & Luxembourg & $\$ 0.22$ \\
Saudi Arabia & $\$ 0.05$ & Cameroon & $\$ 0.09$ & Brazil & $\$ 0.16$ & Austria & $\$ 0.23$ \\
Bahrain & $\$ 0.05$ & Indonesia & $\$ 0.10$ & Croatia & $\$ 0.16$ & Czech Republic & $\$ 0.23$ \\
Ukraine & $\$ 0.05$ & Ecuador & $\$ 0.10$ & Costa Rica & $\$ 0.16$ & Australia & $\$ 0.24$ \\
Malaysia & $\$ 0.06$ & Canada & $\$ 0.10$ & Chile & $\$ 0.16$ & Spain & $\$ 0.25$ \\
Ghana & $\$ 0.06$ & Tanzania & $\$ 0.10$ & Estonia & $\$ 0.17$ & Netherlands & $\$ 0.25$ \\
Pakistan & $\$ 0.06$ & Jordan & $\$ 0.11$ & Israel & $\$ 0.17$ & Liechtenstein & $\$ 0.26$ \\
Bangladesh & $\$ 0.06$ & Albania & $\$ 0.11$ & Senegal & $\$ 0.17$ & Italy & $\$ 0.27$ \\
Russia & $\$ 0.06$ & South Korea & $\$ 0.11$ & Romania & $\$ 0.17$ & United Kingdom & $\$ 0.27$ \\
Nepal & $\$ 0.07$ & Thailand & $\$ 0.12$ & Sweden & $\$ 0.18$ & Ireland & $\$ 0.28$ \\
Nigeria & $\$ 0.07$ & Morocco & $\$ 0.12$ & Poland & $\$ 0.18$ & Japan & $\$ 0.29$ \\
Tunisia & $\$ 0.07$ & Norway & $\$ 0.12$ & Singapore & $\$ 0.18$ & Jamaica & $\$ 0.30$ \\
Belarus & $\$ 0.07$ & Bulgaria & $\$ 0.13$ & Slovakia & $\$ 0.18$ & Portugal & $\$ 0.30$ \\
Georgia & $\$ 0.07$ & South Africa & $\$ 0.13$ & Latvia & $\$ 0.19$ & Belgium & $\$ 0.31$ \\
Mexico & $\$ 0.08$ & Hungary & $\$ 0.13$ & Uruguay & $\$ 0.19$ & Denmark & $\$ 0.33$ \\
China & $\$ 0.08$ & Ivory Coast & $\$ 0.13$ & Slovenia & $\$ 0.19$ & Germany & $\$ 0.35$ \\
\hline \hline
\end{tabular}

Note: Data obtained from https://www.globalpetrolprices.com/electricity prices/ in US\$ terms as of November 2019. 
Table 3: Electricity prices for businesses as of 2019 (per kW)

\begin{tabular}{|c|c|c|c|c|c|c|c|}
\hline Venezuela & $\$ 0.01$ & Russia & $\$ 0.08$ & Bulgaria & $\$ 0.12$ & Singapore & $\$ 0.15$ \\
\hline Libya & $\$ 0.02$ & South Korea & $\$ 0.08$ & Burma & $\$ 0.12$ & Cameroon & $\$ 0.15$ \\
\hline Ethiopia & $\$ 0.02$ & Czech Republic & $\$ 0.09$ & Thailand & $\$ 0.12$ & Poland & $\$ 0.15$ \\
\hline Uzbekistan & $\$ 0.03$ & Canada & $\$ 0.09$ & Philippines & $\$ 0.12$ & Macao & $\$ 0.16$ \\
\hline Zambia & $\$ 0.03$ & Ecuador & $\$ 0.09$ & Romania & $\$ 0.12$ & Switzerland & $\$ 0.16$ \\
\hline Algeria & $\$ 0.04$ & Uruguay & $\$ 0.09$ & Taiwan & $\$ 0.13$ & Guatemala & $\$ 0.16$ \\
\hline Qatar & $\$ 0.04$ & UAE & $\$ 0.10$ & Hungary & $\$ 0.13$ & Mexico & $\$ 0.16$ \\
\hline Kazakhstan & $\$ 0.05$ & Turkey & $\$ 0.10$ & Chile & $\$ 0.13$ & Uganda & $\$ 0.16$ \\
\hline Iraq & $\$ 0.05$ & Malaysia & $\$ 0.10$ & Bolivia & $\$ 0.13$ & Slovakia & $\$ 0.17$ \\
\hline Paraguay & $\$ 0.05$ & Ukraine & $\$ 0.10$ & Peru & $\$ 0.13$ & Austria & $\$ 0.17$ \\
\hline Azerbaijan & $\$ 0.05$ & Estonia & $\$ 0.10$ & Greece & $\$ 0.13$ & Malta & $\$ 0.17$ \\
\hline Kuwait & $\$ 0.05$ & Tanzania & $\$ 0.10$ & Brazil & $\$ 0.13$ & Australia & $\$ 0.17$ \\
\hline South Africa & $\$ 0.06$ & Serbia & $\$ 0.10$ & Croatia & $\$ 0.13$ & Liechtenstein & $\$ 0.17$ \\
\hline Argentina & $\$ 0.06$ & China & $\$ 0.10$ & France & $\$ 0.13$ & Mali & $\$ 0.17$ \\
\hline Georgia & $\$ 0.06$ & Lebanon & $\$ 0.10$ & Belgium & $\$ 0.13$ & Belize & $\$ 0.18$ \\
\hline Iceland & $\$ 0.07$ & Bangladesh & $\$ 0.10$ & Slovenia & $\$ 0.13$ & Kenya & $\$ 0.19$ \\
\hline Saudi Arabia & $\$ 0.07$ & Belarus & $\$ 0.11$ & Pakistan & $\$ 0.14$ & Ivory Coast & $\$ 0.21$ \\
\hline Armenia & $\$ 0.07$ & DR Congo & $\$ 0.11$ & Finland & $\$ 0.14$ & United Kingdom & $\$ 0.21$ \\
\hline Mozambique & $\$ 0.07$ & Nigeria & $\$ 0.11$ & Luxembourg & $\$ 0.14$ & Honduras & $\$ 0.22$ \\
\hline Sri Lanka & $\$ 0.07$ & Israel & $\$ 0.11$ & Netherlands & $\$ 0.14$ & Italy & $\$ 0.22$ \\
\hline Indonesia & $\$ 0.07$ & Botswana & $\$ 0.11$ & Colombia & $\$ 0.14$ & Germany & $\$ 0.22$ \\
\hline Egypt & $\$ 0.07$ & Tunisia & $\$ 0.11$ & Ghana & $\$ 0.14$ & Japan & $\$ 0.22$ \\
\hline Nepal & $\$ 0.08$ & Morocco & $\$ 0.11$ & Hong Kong & $\$ 0.14$ & Costa Rica & $\$ 0.24$ \\
\hline Bahrain & $\$ 0.08$ & USA & $\$ 0.11$ & Latvia & $\$ 0.15$ & Jamaica & $\$ 0.24$ \\
\hline Vietnam & $\$ 0.08$ & Bosnia \& Herz. & $\$ 0.12$ & Spain & $\$ 0.15$ & Denmark & $\$ 0.28$ \\
\hline
\end{tabular}

Note: Data obtained from https://www.globalpetrolprices.com/electricity prices/ in US\$ terms as of November 2019. 